\title{
The Basis of Anticancer Immunity Mechanism Induced by In Situ Vaccination
}

\author{
Anastasia S. Proskurina ${ }^{a \#}$, Vera S. Ruzanova ${ }^{a, b \#,}$ \\ Tamara V. Tyrinova ${ }^{c}$, Dmitry N. Strunkin ${ }^{c, d}$, \\ Svetlana S. Kirikovich ${ }^{a}$, Genrikh S. Ritter ${ }^{a}$, \\ Yaroslav R. Efremov ${ }^{\mathrm{a}, \mathrm{b}}$ and Sergey S. Bogachev ${ }^{\text {a** }}$ \\ ${ }^{a}$ Institute of Cytology and Genetics of the SB RAS \\ Novosibirsk, Russian Federation \\ ${ }^{b}$ Novosibirsk National Research State University \\ Novosibirsk, Russian Federation \\ ${ }^{c}$ Research Institute of Fundamental and Clinical Immunology \\ Novosibirsk, Russian Federation \\ ${ }^{d}$ Research Institute of Molecular Biology and Biophysics \\ Novosibirsk, Russian Federation
}

Received 03.12.2019, received in revised form 29.03.2020, accepted 25.06.2020

\begin{abstract}
The present review is an attempt to characterize the principles of both onset and development of the systemic antitumor immune response triggered by in situ vaccination, which is a new trend in anticancer immunotherapy. Modern methods of cancer immunotherapy usually require the presence of a specific target antigen. The in situ vaccination approach does not need a specific antigen. The determinants necessary for the formation of the immune response are all present at the vaccination site, as tumor cells are lysed by cells of innate immunity, infiltrating the tumor and activated by the treatments. The first part of the review is a compilation of the literature data on causes, circumstances, and factors determining the presence in the local tumor node of the totality of tumor antigens essential for the development of the adaptive antitumor immune response. The second part of the review analyzes possible events of antitumor immune response development due to in situ vaccination using ligandreceptor interaction and antigen-presenting cells activation, based on the data structuring performed previously.
\end{abstract}

(C) Siberian Federal University. All rights reserved

This work is licensed under a Creative Commons Attribution-NonCommercial 4.0 International License (CC BY-NC 4.0).

* Corresponding author E-mail address: labmolbiol@mail.ru

\# These authors contributed equally to this work

ORCID: 0000-0002-7650-4331 (Proskurina A.); 0000-0002-6836-5618 (Ruzanova V.); 0000-0002-7987-2017 (Tyrino-va T.); 0000-0002-3426-4501 (Kirikovich S.); 0000-0003-1573-3795 (Ritter G.); 0000-0002-0649-7543 (Efremov Ya.); 0000-0002-2019-9382 (Bogachev S.) 
Keywords: antitumor immune response, antigen-presenting cells, tumor antigens, in situ vaccination, CpG, OX40 antibodies.

Citation: Proskurina A.S., Ruzanova V.S., Tyrinova T.V., Strunkin D.N., Kirikovich S.S., Ritter G.S., Efremov Ya.R., Bogachev S.S. The basis of anticancer immunity mechanism induced by in situ vaccination. J. Sib. Fed. Univ. Biol., 2020, 13(3), 235-269. DOI: 10.17516/1997-1389-0326

\title{
Основы механизма развития
}

\section{противоопухолевого иммунитета}

\section{при in situ вакцинации}

\author{
А.С. Проскурина ${ }^{\mathrm{a}}$, В.С. Рузанова ${ }^{\mathrm{a}, \overline{6}}$, \\ Т.В. Тыринова ${ }^{\text {в }}$, Д.Н. Стрункин ${ }^{\text {в,г }}$, С.С. Кирикович ${ }^{a}$, \\ Г.С. Риттер ${ }^{\text {a }, ~ Я . Р . ~ Е ф р е м о в ~}{ }^{\text {a, }}$, С.С. Богачев ${ }^{a}$ \\ ${ }^{a}$ Федеральный исследовательский центр \\ Институт изитологии и генетики СО РАН \\ Российская Федерация, Новосибирск \\ ${ }^{6}$ Новосибирский национальный \\ исследовательский государственный университет \\ Российская Федерачия, Новосибирск \\ ${ }^{6}$ Научно-исследовательский институт фундаментальной \\ и клинической иммунологии \\ Российская Федерачия, Новосибирск \\ ${ }^{2}$ Научно-исследовательский институт \\ молекулярной биологии и биофизики \\ Российская Федерация, Новосибирск
}

\begin{abstract}
Аннотация. В обзоре предпринята попытка охарактеризовать принципы возникновения и распространения системного противоопухолевого иммунного ответа при in situ вакцинации новом направлении в экспериментальной иммунотерапии злокачественных новообразований. Современные методы иммунотерапии опухолей, как правило, требуют обязательного наличия специфического антигена-мишени. Подход с использованием in situ вакцинации не требует специфического антигена. Вся совокупность детерминант, необходимых для формирования иммунного ответа, появляется в сайте вакцинации в результате лизиса опухолевых клеток клетками врожденного иммунитета, инфильтрирующими опухоль и активированными в результате проведенных обработок. Первая часть обзора представляет собой систематизацию известных литературных данных в разрезе причин, обстоятельств и факторов, определяющих возможность появления в локальном опухолевом очаге всей совокупности опухолевых антигенов, необходимых для развития противоопухолевого адаптивного иммунитета.
\end{abstract}

равный вклад авторов в работу 
Вторая часть обзора базируется на проведенной систематизации и представляет собой анализ возможных событий развития системного противоопухолевого иммунного ответа при in situ вакцинации с использованием платформы рецептор-лиганд/антигенпрезентирующие клетки на примере синергичного действия CpG олигонуклеотидов и антител OX40.

Ключевые слова: противоопухолевый иммунный ответ, антигенпрезентирующие клетки, опухолевые антигены, in situ вакцинация, CpG, антитела OX40.

Цитирование: Проскурина, А.С. Основы механизма развития противоопухолевого иммунитета при in situ вакцинации / А.С. Проскурина, В.С. Рузанова, Т.В. Тыринова, Д.Н. Стрункин, С.С. Кирикович, Г.С. Риттер, Я.Р. Ефремов, С.С. Богачев // Журн. Сиб. федер. ун-та. Биология, 2020. 13(3). С. 235-269. DOI: 10.17516/1997-1389-0326

\section{Принятые сокращения}

АПК - антигенпрезентирующие клетки, ДК - дендритные клетки,

ADCC - antibody-dependent cellular cytotoxicity - антителозависимая клеточная цитотоксичность,

DBP - vitamin D3-binding protein - белок, связывающий витамин Д,

GcMAF - Gc protein-derived macrophage activating factor - специфический фактор активации макрофагов,

MDSC - myeloid-derived suppressor cells - супрессорные клетки миелоидного происхождения,

NKT - natural killer T cells - натуральные киллерные Т-клетки, субпопуляция лимфоцитов, экспрессирующих как маркеры NK-клеток, так и Т-клеточные дифференцировочные антигены,

NK-клетки - натуральные киллеры,

TCR - T-cell receptor - T-клеточный peцептор,

Teff - эффекторные Т-лимфоциты,

TLR - Toll-like receptor - Толл-подобный рецептор,

Treg - регуляторные Т-лимфоциты.

\section{Введение}

В экспериментальной противоопухолевой иммунотерапии развивается новое на- правление, не базирующееся на системном введении препарата, направленном на активацию определенного звена иммунитета, а представляющее собой такой тип воздействия, при котором одновременно в небольшой области опухоли активируется вся совокупность иммунных клеток, и развивается противоопухолевый иммунитет, сопровождающийся разрушением первичной и дистальных опухолей и выздоровлением организма (Guiducci et al., 2005; Sagiv-Barfi et al., 2018). Такой тип локальной иммунотерапии получил название in situ вакцинации.

В настоящее время рассматриваются многочисленные экспериментальные технологические платформы, использующие различные методические подходы для in situ активации противоопухолевого иммунитета. Это использование онколитических вирусов, манипуляции с инфильтрирующими опухоль миелоидными клетками и лимфоцитами, блокада рецептор-лигандного взаимодействия (например, разрыв опухоль-ассоциированного PD1/PDL1 сигнального пути антителами против молекул контрольных точек PD1, TNF-сигнализация), абляция локальным облучением, локальная радиочастотная, ультразвуковая и криоабляция, инъекции трансформированных клеток, цитокиновая активация, тканевая 
электропорация, а также различные их комбинации (Hammerich et al., 2015; Sersa et al., 2015; Hammerich et al., 2016; Aznar et al., 2017; Bilusic, Gulley, 2017; Marabelle et al., 2017; Murthy et al., 2017; Takahashi et al., 2017).

Локальная иммунотерапия имеет ряд принципиальных преимуществ перед обычной иммунотерапией: 1) доза вводимого в опухолевый очаг препарата существенно ниже в сравнении с его системным введением, что снижает токсичность терапии; 2) в этой связи можно одновременно использовать несколько технологических платформ без опасения развития неконтролируемого токсического эффекта (последствия цитокинового шторма) (Bilusic, Gulley, 2017; Marabelle et al., 2017); 3) создается высокая локальная концентрация препарата, что существенно повышает силу иммунного ответа. Тем не менее основной смысл любой из перечисленных технологических платформ - это активация антигенпрезентирующих клеток (АПК), первичное получение всей возможной совокупности опухоль-ассоциированных антигенов и разрушение супрессорного влияния опухоль-ассоциированной стромы (Marabelle et al., 2017).

Технически подход представляет собой введение в очаг опухолевого роста факторов, активирующих АПК, и факторов, так или иначе запускающих необратимую встречную волну активации АПК и одновременно активирующих клетки врожденного иммунного ответа. Активированные иммунные клетки и сеть образующихся клеточных и гуморальных связей при таком воздействии определяют неизбежность лизиса клеток опухоли в первичном очаге и появления в ограниченном пространстве всей возможной совокупности опухоль-ассоциированных антигенов. Эти антигены вследствие прямого клеточного контакта дендритных клеток (ДК) и разрушающихся клеток опухоли непосредственно попадают во внутренние компартменты ДК. Следствием такого сценария служит появление предельного количества антигенных детерминант и максимально возможного репертуара праймированных, активированных к пролиферации и клональной экспансии эффекторных CD8+ T-клеток. Размножившиеся в селезенке CD8+ T-лимфоциты представляют собой адаптивное звено иммунного противоопухолевого ответа, охватывающего весь организм.

В научной литературе существуют примеры такого рода терапевтических подходов, продемонстрировавших эффективность при лечении перевитых или индуцированных экспериментальных злокачественных новообразований. Как следует из анализа литературных источников, для активации ДК используются CpG-олигонуклеотиды или TNF- $\alpha$ (Zaini et al., 2007; Jensen et al., 2010; Murphy et al., 2014; Sagiv-Barfi et al., 2018).

Для воздействия на другие звенья иммунного ответа применяют моноклональные антитела или другие специфические лиганды. Антитела против молекул контрольных точек PD1 (programmed cell death 1), расположенных на поверхности Т-цитотоксических клеток, превентивно предотвращают их контакт с соответствующими лигандами, расположенными на поверхности АПК, ДК, макрофагов и клеток многих опухолей. Разрыв в PD1/PDL1 сигнального пути сохраняет цитотоксическую активность Т-лимфоцитов. Именно этот принцип используется в новых иммунологических подходах к лечению злокачественных опухолей (Dong et al., 2002; Liu et al., 2007; Jensen et al., 2010; Tang et al., 2015; Farkona et al., 2016; Ключагина и др., 2017; Caяпина, 2017). 
Гликолипиды $\alpha$-галактозилцерамид или $\alpha$-глюкуронозилцерамид также применяют в противоопухолевой экспериментальной терапии. Эти молекулы являются аналогами эндогенного гликолипида изоглоботригексозилцерамида, который представляется в качестве эндоантигена в комплексе с CD1d (фактор, относящийся к группе белков MHC класса I) АПК. Такой комплекс взаимодействует с Т-клеточным рецептором на натуральных киллерных Т-клетках (NKT), что сопровождается их активацией и сверхпродукцией IFN- $\gamma$ (Metelitsa, 2011).

Большое внимание уделяется антителам или генно-инженерным лигандам к рецепторам, относящимся к суперсемейству рецепторов к фактору некроза опухоли (Melero et al., 1997, 1998; Zhang et al., 2007) и, в частности, OX40 (Redmond, Weinberg, 2007; Zaini et al., 2007; Croft, 2010; Jensen et al., 2010; Weinberg et al., 2011; Murphy et al., 2014; Sagiv-Barfi et al., 2018). В различных видах терапии злокачественных опухолей, основанных на взаимодействии с OX40-рецептором, относящимся к указанному выше семейству рецепторов фактору некроза опухоли, применяются не только антитела или генно-инженерные белковые конструкции, но и другие ОX40-агонисты, такие как РНК-аптамеры (Dollins et al., 2008; Pratico et al., 2013; Nozari, Berezovski, 2017) или химические соединения (Song et al., 2014). Эти молекулы также активируют CD4+ Т-лимфоциты, индуцируя их пролиферацию и секрецию ими IFN- $\gamma$, что приводит к развитию адаптивного иммунного ответа. Эксперименты свидетельствуют, что использование таких молекул для индукции системного противоопухолевого иммунного ответа требует в обязательном порядке Fc-фрагмента антител. Эта часть молекулы антитела может быть естественной частью молекулы иммуноглобулина или входить в состав гибридного фактора, используемого в терапии.

В настоящем обзоре предпринята попытка проанализировать начальные события активации противоопухолевого механизма при in situ вакцинации при использовании платформы «рецептор-лиганд с одновременной активацией АПК» на примере синергичного действия $\mathrm{CpG}$ олигонуклеотидов и антител OX40 (Sagiv-Barfi et al., 2018). Для анализа мы взяли именно это исследование, поскольку оно является одним из наиболее ярких демонстраций возможностей использования in situ вакцинации для эрадикации экспериментальных иммуногенных опухолей.

\section{Часть I.}

\section{Принципиальные события,}

инициирующие начало волны

противоопухолевого иммунного ответа при in situ вакцинации

Анализ экспериментально-терапевтического подхода (in situ вакцинация), позволяющего элиминировать иммуногенную опухоль (Guiducci et al., 2005; Sagiv-Barfi et al., 2018), свидетельствует о том, что существуют принципиальные положения, определяющие эффективность терапии.

На наш взгляд, принципиальная схема формирования и развития противоопухолевого иммунитета состоит из нескольких определяющих моментов. Основным и необходимым условием реализации такого подхода является выбор высокоиммуногенного типа экспериментальной опухоли. В техническом плане первое и наиболее важное обстоятельство - это совместное введение препаратов в небольшую область опухолевого очага (in situ). Начало инициирующих событий должно происходить в локальном, ограниченном месте опухолевого роста. Пространственное разделение инициирую- 
щих событий не позволит достичь «критической массы» совокупного индуцирующего потенциала, необходимого для стабилизации и развития возникшего иммунного ответа. Для процесса инициации необходимо, чтобы инициирующие типы клеток находились или в непосредственном контакте, или в непосредственной близости друг к другу. Очаг опухоли должна инфильтрировать достаточная по числу совокупная популяция клеток врожденного иммунитета, отвечающая за неспецифический лизис трансформированных клеток и появление первой волны антигенов. Антигенпрезентирующие ДК и макрофаги должны быть активированы и иметь потенциал «захватывать» появившиеся в непосредственной близости опухолевые антигены. И, наконец, первично активированное иммунное разрушение опухолевых клеток должно непрерывно поддерживаться гуморальным фоном и межклеточными взаимодействиями уже активированных иммунных клеток, инфильтрирующих опухолевый очаг. Таким образом, принципиальная схема развития противоопухолевого иммунитета представляет собой несколько независимых и вытекающих один из другого процессов. Происходит активация (in situ) системы клеток врожденного иммунитета; киллинг клеток первичной опухоли и ее полный лизис; созревание антигенпрезентирующих ДК и активация макрофагов, презентация антигена или in situ или после миграции в периферические лимфоузлы (Талаев, Плеханова, 2014); активация и прайминг системы клеток адаптивного иммунитета антигенами, появившимися в результате первичного лизиса клеток опухоли; амплификация и выход на периферию цитотоксических Т-лимфоцитов; лизис дистальных очагов опухоли системой клеток адаптивного иммунитета; формирование системы клеток последующего дли- тельного иммунного надзора (клеток памяти). Такая форма противоопухолевого ответа предполагает, что две дополняющие друг друга системы задействованы в эрадикации экспериментальных иммуногенных опухолей, описанной в цитируемых выше работах: это система клеток врожденного иммунитета и система клеток приобретенного иммунитета.

Bсе фазы развития противоопухолевого иммунитета имеют многочисленные векторы активации, включающие взаимодействие различных типов клеток, взаимодействие специфических рецепторов и их лигандов, секрецию растворимых молекул, создающих гуморальный фон, поддерживающий развивающийся иммунный ответ. Векторы активации могут существовать независимо и могут пересекаться в различных сочетаниях. Такое положение вещей делает полный интегральный анализ происходящих событий практически невозможным. Тем не менее именно активность системы клеток врожденного иммунитета и первичный лизис неопластических клеток (или любое иное воздействие, индуцирующее локальное появление максимально возможной совокупности опухолевых антигенов) служат первопричиной индукции противоопухолевого иммунитета.

В этой связи в данной части обзора будет дана краткая характеристика возможных механизмов неспецифического лизиса клеток опухоли. Кратко будут охарактеризованы и типы клеток врожденного иммунитета, которые отвечают за неспецифический лизис трансформированных клеток и появление первой волны антигенов. Появление первой волны антигенов составляет основу развития адаптивного противоопухолевого иммунного ответа, которая определяется АПК и CD8+ Т-клетками. 
Возможные принципиальные механизмы

киллинга клеток опухоли

и типы клеток врожденного иммунитета, осуществляющих литическую функцию по отношению

\section{к трансформированной клетке}

Появление антигенного репертуара, который далее приведет к развитию адаптивного иммунного ответа, возможно только в случае лизиса опухолевых клеток в первичном очаге опухоли. При обработке in situ разрушение клеток опухоли может осуществляться несколькими путями. Неспецифическое физическое повреждение клеток происходит при введении препаратов в опухоль. Специфическое разрушение опухолевых клеток будет определяться клетками врожденного иммунитета, обладающими арсеналом литических механизмов, которые будут активированы проведенными обработками. К таким механизмам можно отнеси прямую цитолитическую активность натуральных киллеров (NK-клетки), NKT, макрофагов, нейтрофилов, ДК, CD8+ цитотоксических Т-лимфоцитов и апоптоз, индуцируемый через систему рецепторов смерти. Производным механизмом лизиса клеток опухоли является осуществляемый NK-клетками и некоторыми другими клетками врожденного иммунитета антителозависимый лизис.

Принципиально существуют три варианта разрушения клеток, происходящего за счет активности иммунной системы: 1) прямой осмотический лизис, который характерен для системы комплемента; 2) некротический лизис, который развивается при секреции галогенов и их производных, токсичных соединений азота и кислорода макрофагами и нейтрофилами; 3) запуск генетически запрограммированного апоптоза или некроза (Манских, 2007). Имеются два основных пути реализации клеточной цитотоксичности, свя- занной с индукцией апоптоза: перфорин-зависимый и Fas-зависимый механизм лизиса. В общих чертах эти процессы выглядят следующим образом.

\section{Перфорин-зависимый механизм лизиса}

Этот механизм лизиса реализуется после распознавания антигена клетки-мишени клеткой-киллером, при этом происходят следующие события. Формируется прочный контакт клетки-киллера с клеткой-мишенью или при участии специфических иммунных комплексов (например, NKG2D/MICA, MICB), или при взаимодействии других лиганд-рецепторных пар (например, LFA/ ICAM-1) (Diamond et al., 1991). Происходит реорганизация цитоплазматических гранул и компонентов цитоскелета клеток-киллеров, вследствие чего содержимое гранул выходит в зону межклеточного контакта. Освободившийся из гранул перфорин (в присутствии ионов кальция) активируется и полимеризуется. Через сформированную пору в клетку мишень проникают гранзимы, представляющие собой сериновые протеазы. Гранзимы активируют систему каспаз, которые являются исполнительным механизмом запуска процесса апоптоза (Thiery et al., 2011).

\section{Fas-зависимый механизм лизиса.}

\section{Система реиепторов смерти}

Практически все клетки организма, за исключением клеток иммунопривилегированных тканей, CD8+ цитотоксических Т-лимфоцитов и NK-клеток, имеют в составе цитоплазматической мембраны Fas рецепторы или объединенные в одно семейство, схожие структурно и функционально, TNF- $\alpha$ peцепторы (Janssen et al., 2003; Peter, Krammer, 2003; Wajant et al., 2003; Chakrabandhu et al., 2008; Aggarwal, 2003). Эти рецепторы называются рецепторами клеточной смерти. Для 
всех рецепторов смерти существуют свои лиганды, связь с которыми запускает внутриклеточные механизмы или апоптоза, или клеточного спасения. Охарактеризованы следующие рецепторы смерти и их лиганды, посредством которых индуцируется апоптоз клеток. Это FasR/FasL, TNFR1/TNF- $\alpha$, TRAIR1, TRAIR2/TRAIL и DR3/TL1A.

Для системы рецепторов смерти описан принципиально один механизм индукции апоптоза с некоторыми незначительными различиями. Начало развития апоптотического каскада происходит при физическом взаимодействии рецептора смерти и его лиганда. В результате конформационных изменений молекулы рецептора и следующей за этим активации системы каспаз, передающей апоптотический сигнал, активируется специфический ДНКазный комплекс CAD/ICAD. Запускается апоптотическое разрушение клетки (Philchenkov, 2003; Peter, Krammer, 2003; Wang et al., 2010; Уткин, Новиков, 2012). Для запуска апоптоза FasR/FasL, TNFR1/TNF- $\alpha$ комплексы должны интернализоваться (Kohlhaas et al., 2007; Falschlehner et al., 2009). Ассоциация TRAILR1, TRAILR2/TRAI и DR3/TL1A индуцирует апоптотический каскад без интернализации комплекса во внутренние компартменты клетки. TRAIL3 и TRAIL4 участвуют в запуске антиапоптотической программы. В цитоплазматическом участке молекул этих белков находится «домен спасения». Он ингибирует проведение апоптотического сигнала при связывании с фосфатазой FAP1 (Мисюрин, 2015).

Различные типы клеток врожденного иммунитета способны осуществлять первичный лизис опухолевых клеток. В следующих разделах обзора мы попытаемся ответить на вопрос, какие инициирующие молекулы и клеточные взаимодействия из известных яв- ляются первопричиной инициации развития процесса такого лизиса.

\section{NК-клетки.}

\section{Антителозависимый лизис}

NK-клетки представляют собой систему клеток врожденного иммунитета, которые обладают способностью к контактному цитолизу клеток-мишеней. Кроме того, эти клетки в ответ на активирующий или ингибирующий сигнал секретируют множество цитокинов и хемокинов, которые влияют на другие системы клеток врожденного иммунитета макрофаги, ДК, нейтрофилы, участвуя тем самым в акселерации петли активации врожденного иммунитета и активации адаптивного иммунного ответа (Dennehy et al., 2011).

Литическая функция NK-клеток реализуется тремя литическими механизмами: с участием экзоцитируемых азурофильных гранул (Cooper et al., 2001; Caligiuri, 2008; Thiery et al., 2011), при непосредственном контакте (FasL, TRAIL и др.) с рецепторами смерти на поверхности клеток-мишеней (Kovalenko et al., 2007; Абакушина и др., 2012) и с использованием механизма антителозависимой клеточной цитотоксичности (ADCC) (Gómez Román et al., 2014). В результате активации нескольких литических механизмов формируется синергичный независимый киллинг опухолевых клеток-мишеней через разные активирующие молекулярные пути (Wang et al., 2015).

NK-клетки имеют несколько механизмов распознавания клеток-мишеней, в том числе опухолевых клеток. Существует общепринятая концепция, что в основе клеточного распознавания мишеней и цитолитической активности NK-клеток лежит принцип «утраты своего» (missing self) (Ljunggren, Kärre, 1990; Ito et al., 2006; Biassoni, 2009; Bjorkstrom et al., 2010). Картина представленных на цитоплаз- 
матической мембране МНСІ молекул и их количество распознаются NK-клетками (семейство KIR рецепторов, CD94/NKG2A, другие лектиноподобные белки С типа). Сдерживание литической активности NK-клеток связано с взаимодействием KIR или CD94/NKG2A ингибирующих рецепторов с белками МHCI. Если при контактном взаимодействии клетки-киллера и клетки-мишени, осуществляемом за счет других рецепторов, количество белков МНСІ соответствует опознаваемой NK-клетками «норме», то лизиса клетки не происходит. Если количество или характерный паттерн MHCI белков не опознается NKклетками, то реализуется цитолитическая активность натурального киллера (Le Dréan et al., 1998; Long, 2008; Jamil, Khakoo, 2011). Опухолевые клетки несут на своей цитоплазматической мембране незначительное количество белков МНCI, что делает их главной мишенью цитолитической функции NK-клеток (Le Dréan et al., 1998; Bottino et al., 2005).

В трансформированных клетках постоянно активированы сигнальные каскады, сообщающие клетке о многочисленных разнообразных нарушениях клеточного метаболизма. В норме при таких обстоятельствах через систему р53 запускается апоптоз и клетка лизируется. В случае раковых клеток p53 система инактивирована и апоптоз не происходит. Тем не менее сигналы о нарушениях продолжают возникать и поддерживать системы клеточного наблюдения. Такая перманентная стресс-активация приводит к синтезу и экспрессии на поверхности раковых клеток стресс-индуцированных молекул MICA и MICB, относящихся к семейству неканонических молекул гистосовместимости МНС класса Ic (Groh et al., 1999; Girardi et al., 2001). Экспонирование этих белков на поверхности цитоплазматической мембраны предшествует появлению в клетке анти- гена, не зависит от него и является наиболее ранней манифестацией трансформированной клетки. Представленные на поверхности стресс-индуцированные молекулы опознаются NKG2D рецептором NK-клетки, который индуцирует цитолиз клетки-мишени (Bauer et al., 1999; Jamieson et al., 2002; Biassoni et al., 2003). То есть опухолевые клетки, на которых экспрессированы стресс-индуцированные молекулы, могут подвергаться лизису независимо от количества молекул гистосовместимости MHC класса Ia и Ib (Бережной и др., 2008). Однако если клетка-мишень тем не менее экспрессирует значительное количество молекул МНСІ, то они распознаются ингибиторными рецепторами, сигналы которых блокируют активацию и развитие иммунных реакций. Таким образом, для активации цитолитической активности NK-клеток важен баланс между активационными и ингибирующими сигналами (принцип «наличия или отсутствия») (Piontek et al., 1985).

Основой феномена «неоднозначности в принятии решения - лизировать клеткумишень или нет» NK-клетками является тот факт, что сигнальные молекулы, определяющие передачу активационного и ингибиторного сигналов на этапе «принятия решения», одни и те же, и полярность сигнала определяется их статусом фосфорилирования. Проведение активирующего сигнала запускается фосфорилированием сигнальных молекул при связывании активирующих рецепторов. При связывании ингибиторных рецепторов происходит дефосфорилирование тех же самых сигнальных молекул, что приводит к отмене активирующего сигнала (Le Dréan et al., 1998; Бережной и др., 2008; Абакушина и др., 2012).

NK-клетки имеют еще один универсальный механизм распознавания клеток-мишеней - ADCC. ADCC представляет собой ме- 
ханизм, посредством которого эффекторные клетки, несущие на своей поверхности Fc peцепторы (CD16), могут опознавать и лизировать покрытые антителами таргетные клетки, экспонирующие на своей поверхности опухолевые или патоген-ассоциированные антигены (Gómez Román et al., 2014). Необходимо отметить, что киллинг опухолевых клеток по механизму ADCC также реализуется при активации нейтрофилов, макрофагов, эозинофилов (Peipp et al., 2008; Schneider-Merck et al., 2010; Bryceson et al., 2012).

Проведенный анализ предполагает, что при in situ вакцинации начало литического процесса и его развитие в первую очередь принадлежит именно NK-клеткам. Апоптотически разрушенные опухолевые клетки образуют совокупность опухолевых антигенов, которые поглощаются расположенными в непосредственной близости в опухолевом очаге активированными АПК, что сопровождается развитием адаптивного иммунного ответа.

\section{Макрофаги}

Макрофаги также являются популяцией клеток, немедленно реагирующей на раздражитель в виде трансформированных клеток. Тем не менее эти фагоцитирующие клетки первоначально должны быть активированы. Активация макрофагов осуществляется активированными Т-хелперами 1-го типа при физическом контакте клеток или паракринно цитокинами. Активация макрофагов на уровне транскрипции генов наблюдается через час после добавления к культуре клеток активирующего коктейля цитокинов, а начало секреции активных молекул происходит через 24 ч инкубации. Активация макрофагов через презентацию антигенов занимает от одного до нескольких (5-7) дней после контакта с антигеном. Эти факты предполагают, что макрофаги при указанном варианте со- бытий начинают цитолитическое действие во втором эшелоне активации противоопухолевого врожденного иммунного ответа in situ (Зенков и др., 2007; Монастырская и др., 2008; Yue et al., 2012; Никонова и др., 2017; Чердынцева и др., 2017). В дополнение к сказанному известно, что макрофаги, инфильтрирующие опухоль, поляризуются в проопухолевые макрофаги M2 фенотипа и функционируют как супрессоры Т-лимфоцитов (для детализации см. раздел «Нейтрофилы»). Это означает, что М2-макрофаги опухолевой стромы с малой долей вероятности принимают участие в формировании первой волны опухолевых антигенов.

Описан путь активации макрофагов, связанный с гликозидазной активностью «воспаленных» Т- и В-лимфоцитов, который определяется превращением белка, связывающего витамин Д3 (DBP), в специфический активатор макрофагов (GcMAF) (Greilberger, Herwig, 2020; Останин и др., 2019). Гликозилированный DBP содержит один трисахарид в позиции 420 остатка треонина, состоящий из $\mathrm{N}$-ацетилгалактозамина с двумя разветвленными остатками сахаров галактозы и сиаловой кислоты. Известно, что в зоне воспаления (опухолевый очаг характеризуется постоянно текущим воспалительным процессом) на цитоплазматической мембране активированных воспалительным процессом В- и Т-клеток экспонируются ферменты $\beta$-галактозидаза и сиалидаза соответственно. В результате сайт-специфического двойного дегликозилирования DBP конвертируется в GcMAF, содержащий остаточный сахар $\mathrm{N}$-ацетилгалактозамин (GalNAc) (Yamamoto, Kumashiro, 1993; Yamamoto et al., 2008).

Можно предположить, что секретируемые медиаторы воспаления индуцируют выход на цитоплазматическую мембрану лимфоцитов специфических гликозидаз и 
что этот процесс является более ранним событием в активации лимфоцитов по сравнению с их антиген-зависимой активацией. В работах (Homma, Yamamoto, 1990; Yamamoto, Kumashiro, 1993; Yamamoto et al., 2008) показано, что культивирование Т- и В-лимфоцитов в течение 30 мин в присутствии синтетического аналога мембранно-связанных фосфолипидов додецилглицерола приводит к способности этих клеток конвертировать DBP в GcMAF. При этом сам процесс активации макрофагов «воспаленными» Т- и В-лимфоцитами занимает в эксперименте 1-2 ч. Это означает, что постоянно находящийся в плазме крови DBP может быть «немедленно» конвертирован в активирующий макрофаги фактор (GcMAF) специфическим дегликозилированием. Этот процесс может составлять основу первичного лизиса раковых клеток макрофагами, активированными таким путем.

Известно, что различные типы клеток, включая опухолевые, экспрессируют на своей поверхности CD1d-молекулы главного комплекса гистосовместимости. CD1d-молекулы имеют гидрофобную антиген-связывающую бороздку, способную селективно «заякоривать» процессированные гликолипидные антигены (East et al., 2014; Zajonc, Girardi, 2015; Акинфиева и др., 2010; Webb et al., 2016). Для клеток опухоли показана повышенная экспрессия CD1d на цитоплазматической мембране, которая связана с изменениями метаболизма клетки (Subrahmanyam et al., 2014; Webb et al., 2016). В некотором смысле можно считать, что CD1d, с повышенной эффективностью экспрессирующийся на поверхности трансформированной клетки, является еще одним стресс-сигналом, маркирующим опухолевую клетку. Именно липидные антигены в составе CD1d, контактируя с Т- и В-лимфоцитами, могут служить «спусковым механизмом» для появления на поверхности инфильтрирующих опухоль Т- и В-лимфоцитов специфических гликозидаз и следующей за этим конверсии DBP в GcMAF и активации макрофагов. В эксперименте, как было сказано выше, этот процесс занимает 1-2 ч и при экстраполяции на условия in vivo может считаться немедленным ответом врожденной иммунной системы на стимул. Именно таким образом активированные макрофаги могут входить в группу клеток, участвующих в появлении первой волны антигенов опухолевых клеток в экспериментах по in situ вакцинации. Следует отметить, что активированные таким образом макрофаги осуществляют свои профессиональные функции, в частности фагоцитоз, используя $\mathrm{Fc}$ рецептор-опосредованный механизм (Ngwenya, Yamamoto, 1985, 1986; Yamamoto, Ngwenya, 1987).

Макрофаги способны лизировать клетку многими описанными для других цитотоксических клеток механизмами (Fas/FasL, TRAIL/TRAILR, TNF- $\alpha /$ TNF- $\alpha$ R, ADCC). Известен малоизученный механизм литической активности макрофагов, направленный на клетки опухоли и связанный с синергичным действием хитотриозидазы и протеаз (Pan, 2012). Тем не менее считается, что одним из основных механизмов цитотоксичности макрофагов является индукция апоптоза или некроза клетки-мишени секретируемыми макрофагами продуктами перекисного окисления, оксидом азота (NO) и свободными формами кислорода.

Активированные макрофаги относятся к противоопухолевым клеткам М1 фенотипа, способным разрушать опухолевые клетки. Предполагается, что активированные периферические макрофаги M1 фенотипа, впервые попавшие в опухолевый очаг, но не опухоль-ассоциированные M2 фагоциты, могут принимать участие в первичном ли- 
зисе опухолевых клеток до момента их проопухолевой поляризации. В другом случае проведенные терапевтические обработки могут стимулировать процесс реполяризации опухоль-ассоциированных макрофагов в опухоль-реактивный фенотип М1. При таких условиях M1 макрофаги могут участвовать в образовании первой волны опухолевых антигенов.

\section{Нейтрофилы}

Нейтрофилы - это еще один тип клеток иммунной системы, которые инфильтрируют опухоль и обладают цитолитической активностью (Pericle et al., 1996; Igney et al., 2005; Brandau, 2013). Они могут осуществлять лизис, используя механизм дегрануляции азурофильных и специфических гранул (Lichtenstein et al., 1988; Segal, 2005). Также нейтрофилы секретируют цитокины, в том числе TNF- $\alpha$, индуцирующий апоптоз раковых клеток через систему рецепторов смерти (Di Carlo et al., 2001). Ключевая роль в литической активности нейтрофилов отводится секретируемым ими активным формам кислорода и азота, а также галогенов, включая гипохлорную кислоту.

Фагоцитоз уже разрушенных раковых клеток или раковых клеток, опсонизированных антителами при взаимодействии Fc-рецептора нейтрофилов, приводит к активации фагоцитов. Лизис раковых клеток сопровождается нарастающим увеличением количества антигенного материала в опухолевом очаге (Dallegri et al., 1991; Di Carlo et al., 2001; Jabłońska et al., 2005; Klebanoff, 1999; Segal, 2005; Мальцева, Сафронова, 2009; Gómez Román et al., 2014).

Следует отметить, что такая цитотоксическая активность нейтрофилов характерна только для опухоли на начальных этапах развития. Это связано с тем, что развива- ющаяся опухоль инициирует быструю Н2 проопухолевую реполяризацию Н1 опухольреактивных нейтрофилов. И, таким образом, на более поздних стадиях развития опухоли нейтрофилы, инфильтрирующие неопластический очаг, проявляют проопухолевую активность. Такие нейтрофилы представляют собой часть популяции супрессорных клеток миелоидного происхождения (MDSC) опухоль-ассоциированной стромы (De Larco et al., 2004; Knaapen et al., 2006; Zhdanova et al., 2007; Кулаков и др., 1999; Лисяный, Лисяный, 2018). В настоящее время установлено, что MDSC (для мышиной модели) представлены двумя наиболее многочисленными популяциями. Это гранулоцитарная или полиморфноядерная фракция MDSC, несущая маркеры CD11b+Lyc6G+Lyc6Clow и морфологически схожая с нейтрофилами, и моноцитарная, несущая маркеры CD11b+Lyc6G-Lyc6Chigh и морфологически схожая с моноцитами. Характерной особенностью обеих популяций клеток является супрессия иммунных клеток, инфильтрирующих опухоль. Основная мишень супрессии - Т-лимфоциты. Супрессия осуществляется различными механизмами и зависит от различных факторов, включая CD62-ADAM17 и Gal-9-TIM3-взаимодействие, аргиназу 1, iNOS, TGF $\beta$, IL-10, COX-2, VEGF, TGF betta 1, индоламин2-3-диоксигеназу (IDO) (Corzo et al., 2010; Gabrilovich, 2017; Kumar et al., 2016; Li et al., 2009; Medina-Echeverz et al., 2014; Petty, Yang, 2017; Atretkhany, Drutskaya, 2016; Чердынцева и др., 2017).

Проведенный анализ предполагает, что активированные нейтрофилы так же, как и макрофаги в случае их первичного попадания в опухолевый очаг или Н1 реполяризации после проведенных обработок, могут принимать участие в первичном лизисе опухолевых клеток. 
NKT

Этот тип клеток относится к классу лимфоцитов, экспрессирующих маркеры NKклеток CD16, CD56 и Т-клеточные дифференцировочные антигены CD3, CD4, CD8. NKT экспрессируют TCR, который участвует в распознавании липидных антигенов, связанных с молекулой гистосовместимости CD1d, экспрессирующейся на АПК макрофагах, ДК, B-лимфоцитах. Показано, что CD1d может сверхэкспрессироваться на поверхности опухолевых клеток, что отражает изменение клеточного метаболизма (Webb et al., 2016). Это означает, как уже было отмечено, что CD1d может представлять собой еще один стресссигнал, свидетельствующий о трансформированности клетки.

Стимуляция NKT происходит при связывании TCR NKT с CD1d. Стимулированные NKT в течение 1-2 ч начинают активную секрецию цитокинов IFN- $\gamma$ и TNF- $\alpha$. Такой быстрый ответ на стимул, по-видимому, связан с присутствием предшественников цитокинов в инфламмасомах до активации клеток (Behar, Cardell, 2000; Sköld, Behar, 2003; Godfrey, Kronenberg, 2004; van Dommelen, Degli-Esposti, 2004; Chung et al., 2005; Bendelac et al., 2007; Webb et al., 2016). Считается, что NKT вносят минимальный вклад в прямой лизис клеток опухоли. Основное действие этого типа клеток связано с активной продукцией цитокинов, действующих как стимулирующий сигнал для активации NK и CD8+ Т-лимфоцитов (Smyth, Godfrey, 2000; Street et al., 2001; Акинфиева и др., 2010).

Имеются данные о прямой цитолитической активности NKT в отношении M2 макрофагов и MDSC, инфильтрирующих опухоль. Этот факт означает, что NKT могут опосредованно, через уменьшение числа опухоль-ассоциированных макрофагов и MDSC, влиять на опухоль. Также этот факт может означать, что при определенных условиях в отношении неопластических клеток может осуществляться прямая цитолитическая активность NKT (Zaini et al., 2007; Акинфиева и дp., 2010; Croft, 2010; Metelitsa, 2011).

\section{Цитотоксическая активность ДК}

Наряду с классическими эффекторными клетками (NК-клетки, цитотоксические Т-лимфоциты), киллерной активностью против опухолевых клеток-мишеней обладают ДК. На текущий момент цитотоксическая функция продемонстрирована для различных типов ДК (миелоидных ДК, в том числе и клеток Лангерганса, плазмоцитоидных ДК, ДК моноцитарного происхождения) (Fanger et al., 1999; Lu et al., 2002; Stary et al., 2007; Le Poole et al., 2008), хотя механизмы ее реализации и биологическая значимость остаются во многом неизученными. Как и классические эффекторные клетки, ДК экспрессируют медиаторы грануло-опосредованной цитотоксичности перфорин и гранзим Б, а также молекулы семейства TNF (TRAIL, FasL, TNF- $\alpha$ ), опосредующие рецептор-зависимую цитотоксичность.

Показано, что ДК обладают прямым цитолитическим действием против различных опухолевых линий (Janjic et al., 2002; Stary et al., 2009; Tyrinova et al., 2013; Hira et al., 2014), осуществляемым через механизмы запуска апоптоза (Vanderheyde et al., 2001; Lu et al., 2002; Yu et al., 2002; Майборода, 2013). Установлено, что медиаторами цитотоксической активности являются незрелые ДК (Matsui et al., 2009; Fanger et al., 1999; Lu et al., 2002), при этом в процессе созревания их цитотоксическая активность снижается или полностью исчезает (Buelens et al., 1997; Lu et al., 2002; LaCasse et al., 2011). Можно предположить, что именно незрелые ДК (входящие в популяцию инфильтрирующих опухоль MDSC) 
выполняют функцию киллерных клеток, которые лизируют опухолевую клетку.

Таким образом, ДК также можно отнести к популяции клеток, инфильтрирующих опухоль, от активности которых зависит появление первых опухоль-ассоциированных антигенов, требующихся в качестве материала для развития системного иммунного ответа при in situ вакцинации. Логично предположить, что лизис, осуществляемый этими клетками, сопровождается немедленным поглощением ими материала разрушенных клеток опухоли непосредственно в месте произошедших деструктивных событий. Нагруженные антигеном зрелые ДК промотируют активацию и экспансию антиген-специфичных Т-клеток.

\section{Цитокины и их роль}

\section{в инициирующих событиях и поддержании индуцированного иммунного ответа}

В конце проведенного анализа необходимо кратко определить положение цитокиновой поддержки при «завязке» противоопухолевого иммунного ответа в опухолевом очаге при условии активации киллерных функций иммунных клеток, инфильтрирующих опухоль. Клетки секретируют цитокины в небольшом объеме опухолевого очага, что позволяет непрерывно поддерживать их высокую локальную концентрацию. Это создает условия для длительного поддержания иммунных клеток в активном состоянии. Одновременно при активации на цитоплазматической мембране инфильтрирующих опухоль иммунных клеток экспрессируются многочисленные специфические рецепторы или их лиганды, а также рецепторы к различным цитокинам. То есть клетка готова в любом формате отвечать на специфическое взаимодействие с агонистами.

Активированные иммунные клетки, инфильтрирующие опухоль, секретируют в очаге опухолевого роста практически всю известную палитру цитокинов, хемокинов и факторов роста, которые создают гуморальный фон перманентного самоподдержания их активного состояния. Четыре из них формируют базовые векторы поддержания иммунных реакций клеток иммунной системы, инфильтрирующих опухоль. Это IFN- $\gamma, \mathrm{TNF}-\alpha$, IL-12 и IL-2.

IFN- $\gamma$ прямо стимулирует клетки иммунной системы, такие как макрофаги и NK-клетки, повышает синтез молекул белков МНС классов I и II и активирует иммунопротеасомы. Высокий уровень молекул MHCII обеспечивает презентацию процессированных (включая раковые) антигенов Т-хелперам 1-го типа. Т-хелперы 1-го типа, в свою очередь, выделяют цитокины, которые координируют активность других клеток иммунной системы (Кадагидзе, 2003; Schroder et al., 2004; Серебренникова, Семинский, 2008; Billiau, Matthys, 2009; Луцкий и др., 2015).

TNF- $\alpha$ и его рецепторы формируют сигнальную систему широкого спектра действия, включая регуляцию врожденного и адаптивного иммунного ответа. TNF- $\alpha$ индуцирует активацию нейтрофилов, макрофагов, ДК, а также их хемотаксис. В макрофагах и нейтрофилах под влиянием TNF- $\alpha$ повышается образование активных форм кислорода, которые вызывают деструкцию мембран и гибель клетки-мишени по механизму некроза (Cеребренникова, Семинский, 2008; Wu, Hymowitz, 2010; Дунаев и др., 2012; Olmos, Lladó, 2014).

IL-12 является важным иммунорегулирующим цитокином, который продуцируют АПК. Секреция IL-12 регулирует врожденный иммунный ответ и определяет развитие адаптивного иммунного ответа (Akira, 2000; Trinchieri, 2003; Del Vecchio et al., 2007; Cepeбренникова, Семинский, 2008; Hamza et al., 2010; Li, 2015). 
IL-2 имеет важное значение для появления и развития иммунного ответа. Этот цитокин индуцирует пролиферацию В-лимфоцитов, активирует цитотоксические Т-лимфоциты и макрофаги, стимулирует NK-клетки (Кадагидзе, 2003; Серебренникова, Семинский, 2008; Malek, 2008; Boyman, Sprent, 2012).

Первичная реакция клеток иммунной системы на распознавание неопластических клеток заключается в секреции воспалительных цитокинов, ключевыми из которых являются IFN- $\gamma$ и TNF- $\alpha$. Макрофаги в ответ на распознавание опухолей секретируют TNF- $\alpha$, а при активном фагоцитозе спектр цитокинов, продуцируемых макрофагами, увеличивается и включает продукцию IL-12, IL-1, IL-6, IL-8, IFN- $\gamma$, CSF. NK-клетки, T-лимфоциты и NKT в результате активации секретируют IFN- $\gamma$. IFN- $\gamma$ стимулирует дозревание ДК, активирует макрофаги и CD8+ Т-лимфоциты. 3релые ДК начинают секрецию IL-12, который, в свою очередь, стимулирует продукцию IFN- $\gamma$ и IL-2. Это в совокупности дополнительно стимулирует киллерные системы иммунных клеток, инфильтрирующих опухоль.

Таким образом, для цитокинов начальной фазы развития иммунного ответа характерно взаимно активирующее и взаимно усиливающее действие. Последующие цитокиновые каскады в той или иной степени унифицированы и связаны с цитокинами, определяющими формирование базовых векторов поддержания иммунных реакций инфильтрирующих опухоль клеток. IFN- $\gamma$ активирует клетки, которые начинают секретировать TNF- $\alpha$, и наоборот, TNF- $\alpha$ создает условия для миграции в данную область клеток, способных секретировать IFN- $\gamma$. IL-12 и IL-2 усиливают синтез TNF- $\alpha$ и IFN- $\gamma$ и стимулируют продукцию этих цитокинов в неактивированных клетках (Бережной и др., 2008).
В такой стохастической неопределенности создается взаимосвязанная, самоподдерживающаяся гуморальная сеть, в которой происходят процессы, связанные с межклеточным взаимодействием и направленные на киллинг трансформированных клеток.

Дополнительно, на наш взгляд, необходимо упомянуть о роли системы Toll-like рецепторов (TLR) в событиях активации противоопухолевого иммунного ответа при in situ терапии. Известно, что эта группа рецепторов может экспрессироваться как иммунными, так и опухолевыми клетками. При активации TLR клетки начинают секретировать различные цитокины и кофакторные молекулы. Стимуляция TLR, экспрессируемых иммунными клетками, является одним из терапевтических подходов, используемых для усиления противоопухолевой активности клеток врожденного иммунитета (например, CpG). При стимуляции TLR, экспрессируемых клетками опухоли, наблюдается активация пролиферации, развитие устойчивости к химиотерапии и увеличение общей выживаемости опухолевых клеток. Это означает, что для формирования устойчивого противоопухолевого ответа при in situ терапии необходимо создание условий для смещения баланса в направлении активации иммунных клеток опухолевой стромы в противовес супрессорной активности клеток опухоли (Dajon et al., 2017).

\section{Часть II.}

\section{Последовательность}

принципиальных событий активации противоопухолевого иммунитета

\section{и участники этих событий}

на примере in situ вакцинации

с использованием CpG олигонуклеотидов

и антител к рецептору OX40

Как уже было отмечено, одной из наиболее ярких демонстраций возможностей 
использования in situ вакцинации для эрадикации экспериментальных иммуногенных опухолей являются результаты исследования (Sagiv-Barfi et al., 2018), в котором охарактеризован терапевтический противоопухолевый эффект синергичного действия $\mathrm{CpG}$ и антител к OX40 (платформа активации противоопухолевого иммунитета «рецептор-лиганд/ АПК»).

Поскольку работа экспериментальная, в ней не рассматриваются все возможные варианты активации противоопухолевого иммунного ответа при in situ вакцинации $\mathrm{CpG}$ и антителами к OX40. В этой связи в дополнение к результатам, описанным в цитируемой работе, нами был проведен анализ литературных источников, позволивший расширить возможный круг клеток-мишеней, участников процесса индукции противоопухолевого иммунитета, которые могут быть активированы совместным введением в опухолевый очаг всего двух активаторов: $\mathrm{CpG}$ и антител к рецептору OX40. Ниже рассмотрены детали принципиальных событий такой активации.

Первичная активация иммунных клеток, находящихся в тесном контакте между собой и с опухолевыми клетками, происходит в малом ограниченном объеме опухолевого очага, т.е. in situ, одновременно по нескольким векторам активации. В таких условиях вся совокупность опухоль-инфильтрирующих клеток находится в динамическом физическом контакте друг с другом в различных сочетаниях, образуя меняющийся контактный «калейдоскоп». При такой внутренней организации любой сигнал может передаваться без задержки, поскольку при этом отсутствует элемент «стохастического дистантного поиска или хемокин-опосредованной миграции». Указанная фаза в развитии системного иммунного ответа главенствующая, поскольку именно здесь впервые появ- ляются (активируются) клетки, лизирующие опухоль, и впервые появляются опухолевые антигены, «захватывающиеся» активированными ДК и макрофагами, что служит основой развития адаптивного иммунного ответа. В этой связи одной из целей настоящей части обзора выступает попытка охарактеризовать причинно-следственные связи, определяющие завязку и развитие противоопухолевого иммунитета при in situ вакцинации с использованием $\mathrm{CpG}$ и антител к ОХ40. В разделе охарактеризованы реперные качественные позиции, позволяющие в той или иной мере экстраполировать полученный результат на имеющуюся онтологическую действительность и оценить возможный реальный ход событий.

\section{Реперные характеристики развития противоопухолевого иммунитета}

Противоопухолевый иммунитет связан с активностью Т-клеток. Для развития иммунитета нужны как CD4+, так и CD8+ Т-лимфоциты. Деплеция любого из указанных типов клеток по отдельности или вместе полностью отменяет развитие системного иммунного ответа при введении $\mathrm{CpG}$ и антител к ОХ40. Оба типа Т-клеток, выделенных из мышей, предварительно обработанных CpG и антителами к OX40, продемонстрировали противоопухолевый ответ. Показано, что в сайте вакцинации при введении $\mathrm{CpG}$ и антител к рецептору OX40 число обоих типов Т-клеток немедленно возрастает. Через 24 ч количество этих клеток возрастает в селезенке, через 5 суток - в дистально растущей опухоли. Индивидуально выделенные инфильтрирующие опухоль Т-клетки при обработке $\mathrm{CpG}$ в системе ex vivo не активируются. Также при деплеции из опухоли макрофагов и ДК, т.е. мажорных популяций миелоидных клеток, инфильтрирующих опухоль, остав- 
шиеся Т-клетки не способны индуцировать иммунный ответ после введения $\mathrm{CpG}$. Этот факт является первым принципиальным моментом в оценке развития противоопухолевого иммунитета и означает, что именно миелоидные клетки, инфильтрирующие опухоль, получив активирующий $\mathrm{CpG}$ сигнал (через TLR-9), определяют развитие иммунного ответа, в том числе через активацию обеих популяций Т-клеток. Оказалось, что эффект иммунизации связан с секрецией миелоидными клетками цитокинов IL-12, IFN- $\gamma$, TNF- $\alpha$, но не IL-2, IL-4, IL-10, GM-CSF.

MDSC представляют собой группу костномозговых предшественников на различных стадиях дифференцировки, а также зрелые макрофаги, ДК, нейтрофилы, тучные клетки. Опухоль за счет секреции IL-10, GMCSF, VEGF, TGF $\beta$, а также за счет клеточных контактов формирует протуморогенный фенотип у всех миелоидных клеток, инфильтрирующих опухоль. Иммунологическая толерантность достигается вследствие анергии Т-лимфоцитов и дисрегуляции их пролиферации, редукции антигенпрезентирующего потенциала ДК и стимуляции экспрессии PD1L на ДК, что приводит к лизису Т-лимфоцитов и ингибированию последующего Т-клеточного иммунитета (Kottschade et al., 2016; Sgambato et al., 2016). Ассоциированные с опухолью макрофаги приобретают М2 фенотип, продуцируют большое количество IL-10, при этом репрессируется продукция IL-12 (активатора ДК). Также происходят изменения в метаболизме NO синтетазы и аргиназы, что приводит к увеличению токсичности макрофагов по отношению к Т-лимфоцитам и усилению пролиферации опухолевых клеток (Lewis, Pollard, 2006; Martinez et al., 2009; Medina-Echeverz et al., 2014). Сказанное выше означает, что инфильтрирующие опухоль ДК и макрофаги, основные антигенпрезентирующие клетки, не способны выполнять свои профессиональные функции. Тем не менее известно, что в другой противоопухолевой терапии с использованием антител против IL-10R и $\mathrm{CpG}$, при проведении которой также показана полная эрадикация опухоли и отдаленных метастаз, происходит смена поляризации макрофагов с М2 на M1 фенотип (Vicari et al., 2002; Guiducci et al., 2005; Krutzik, Nolan, 2006). Это важнейшее наблюдение свидетельствует о том, что обработки с использованием антител к рецепторам факторов, определяющих развитие иммунного ответа, на фоне введения $\mathrm{CpG}$ в состоянии снять иммунологическую толерантность как минимум с популяции макрофагов, инфильтрирующих опухоль.

Помимо активации миелоидных клеток, инфильтрирующих опухоль, при введении $\mathrm{CpG}$ индуцируется экспрессия рецептора OX40 на различных клетках и в первую очередь на Т-лимфоцитах, что, по-видимому, является вторым принципиальным моментом в развитии противоопухолевого иммунитета. А введение антител к ОХ40 служит вторым шагом в укреплении первых иммунных реакций, развитии иммунитета и осуществлении лизиса опухоли в очаге in situ вакцинации и дистальных опухолевых очагах. В цитируемой работе (Sagiv-Barfi et al., 2018) установлено, что введение $\mathrm{CpG}$ индуцирует экспрессию OX40 на Т-регуляторных (Treg) и Т-эффекторных (Teff) лимфоцитах. Появление OX40 на Treg ингибирует их активность, а появление на Teff, наоборот, усиливает активность этих клеток. Это еще одно указание на то, что при названных обработках происходит смена поляризации клеток, инфильтрирующих опухоль, с протуморогенных на опухоль-реактивные.

Третий принципиальный момент в развитии иммунитета в структуре терапии работы (Sagiv-Barfi et al., 2018) - необходимость 
участия в «завязке» и продолжении иммунных реакций Fc-фрагмента антител.

В работе не приводятся данные об экспрессии ОХ40 рецептора на других типах клеток и в особенности на клетках, от активности которых зависит появление первой волны раковых антигенов, что служит первоосновой адаптивного иммунитета. В этой связи мы провели анализ возможности активации и проявления литических свойств по отношению к клеткам опухоли у иммунных клеток, инфильтрирующих опухоль, не описанных в цитируемой работе, на поверхности которых, согласно литературным данным, присутствуют рецепторы ОХ40. Мы предполагаем, что при проведенной терапии могли возникнуть не описанные в работе взаимодействия, связанные с введением антител к OX40 в очаг опухоли, которые послужили дополнительным или равнозначным стимулом(ами) для развития противоопухолевого иммунитета в результате специфического лигирования.

\section{CpG. Вектор активации.}

\section{Краткий анализ последствий}

При инъекции фактора $\mathrm{CpG}$ происходит активация АПК и в первую очередь ДК. $\mathrm{CpG}$ (Krieg, 2003), а также TNF-a (Brunner et al., 2000), препарат «Панаген» (геномная фрагментированная ДНК человека) (Alyamkina et al., 2010, 2012), липополисахарид (Leifer, Medvedev, 2016) активируют ДК, используя различные механизмы активации. CpG при взаимодействии с TLR9 ДК индуцирует активацию их антигенпрезентирующих свойств. После взаимодействия ДК с указанным фактором происходит быстрое увеличение синтеза многочисленных молекул, участвующих в развитии и поддержании иммунного ответа, таких как MHCII, MHCI, CD80, CD86, CD137L, OX40L, CD1d, TNF-a, IFN- $\alpha / \beta$, IL-12, IL-18. Появление этих факторов на мембране
ДК и/или секреция синтезирующихся цитокинов приводят к расширению спектра участников, распространяющих первичный сигнал, активирующий иммунный ответ (Redmond, Weinberg, 2007; Croft, 2010; Metelitsa, 2011). Возникает сообщество активированных иммунных клеток, экспрессирующих палитру специфических молекул, способствующих индукции другого вектора иммунного ответа, связанного с инъекциями антител к рецептору OX40.

Можно привести несколько примеров передачи первичного активирующего сигнала, полученного ДК, другим типам иммунных клеток. Так, активация ДК $\mathrm{CpG}$ стимулирует синтез МHCII, что сопровождается повышением эффективности захвата антигена, его процессинга и презентации Т-лимфоцитам. Достаточность TCR-MHCII сигнала активированных ДК стимулирует экспрессию OX40 рецептора на Teff. В то же время экспрессия OX40 на Treg ингибируется, причем пропорция Teff/Treg в сайте обработки меняется в сторону увеличения Teff (Sagiv-Barfi et al., 2018). Такое соотношение клеток и разница в уровне экспрессии ОХ40 являются факторами, от которых зависит индукция системного иммунного ответа (Sagiv-Barfi et al., 2018). По-видимому, именно ДК различной степени зрелости, инфильтрирующие опухоль и составляющие часть популяции MDSC, определяют стимуляцию экспрессии ОХ40 на различных типах клеток в экспериментах, связанных с активацией опухоль-ассоциированных миелоидных клеток. Предполагается, что такая стимуляция определяется секрецией активированными клетками IL-12, TNF- $\alpha$ и IFN- $\gamma$ (Zaini et al., 2007; Jensen et al., 2010; Sagiv-Barfi et al., 2018).

Через синергичное взаимодействие CD80 и CD86 ДК с кофакторной молекулой CD28 на наивных Т-клетках происходит актива- 
ция последних. Это приводит к увеличению Т-клеточной клональной экспансии, синтезу антиапоптотических молекул (Bcl-xL), продукции ими IL-2.

Взаимодействие других лигандов, экспрессирующихся на ДК, активированных обработкой $\mathrm{CpG}$, с соответствующими кофакторными молекулами, экспрессирующимися на Т-клетках, такими как негативный регулятор активации Т-клеток CTLA-4, несколько членов TNF-а семейства: 4-1BB, CD27, CD40, а также OX40, приводит к оптимизации дифференцировки CD4+ и CD8+ T-клеток и высокой степени их выживаемости (Redmond, Weinberg, 2007). Так, например, CD137L, член TNF- $\alpha$ семейства белков, экспрессируется активированными АПК. Взаимодействие 1-4ВВ Т-клеток и его естественного лиганда $\mathrm{CD} 137 \mathrm{~L}$ на ДК является костимуляторным сигналом для полной активации CD4+ и CD8+ Т-лимфоцитов. Показано, что активированные таким образом Т-клетки обладают выраженной противоопухолевой цитотоксичностью (Zhang et al., 2007).

Фактор CD1d экспрессируется на ДК вследствие их CpG/TLR-зависимой активации. CD1d относится к MHC классу I и способен представлять эндогенные и экзогенные гликолипиды. Именно этот лиганд ответствен за один из путей активации NKT. Показано, что комплекс синтетического аналога эндогенных гликолипидов $\alpha$-галактозилцерамида и CD1d в синергизме с кофакторным взаимодействием OX40L ДК и OX40 рецептора NKT активирует NKT к синтезу и секреции IFN- $\gamma$ (Zaini et al., 2007; Metelitsa, 2011).

Взаимодействие OX40L и OX40 рецептора, экспрессирующихся на различных иммунных клетках, регулирует интегральный иммунный ответ совокупной клеточной системы. Причем каждая из таких лиганд/рецептор пар является частью этой регуляции.
Так, например, индукция экспрессии OX40L на ДК и его взаимодействие с OX40 на NKT и CD4+ T-лимфоцитах - критичные и необходимые факторы для развития противоопухолевого ответа, связанного с активностью этих популяций клеток. Отсутствие OX40L на ДК полностью отменяет противоопухолевое действие $\mathrm{CD} 8+$ T-лимфоцитов, т.е. нарушается антиген-специфический клеточный иммунный ответ. Основным элементом такого нарушения, как следует из результатов экспериментов, выступает нарушение взаимодействия OX40L ДК и OX40 рецептора на CD4+ T-клетках и взаимодействия OX40L и OX40 рецептора на NKT (Redmond, Weinberg, 2007; Croft, 2010; Jensen et al., 2010; Murphy et al., 2014).

Таким образом, в результате инъекций $\mathrm{CpG}$ в начале цепи событий происходит следующее. Антигенпрезентирующие ДК активируются и: 1) становятся готовыми принять раковый антиген; 2) активируют NKT, CD4+ и $\mathrm{CD} 8+$ T-лимфоциты; 3) осуществляют прямой лизис раковых клеток; 4) стимулируют или секретируют сами IFN- $\gamma$, IL-12, TNF- $\alpha$, IFN- $\alpha / \beta$, IL-18 и создают таким образом условия для активации клеток адаптивного иммунитета. Именно ДК - фактор, объединяющий все звенья иммунного ответа.

\section{Антитела к ОХ40. Вектор активации. Краткий анализ последствий}

В анализируемой терапии (Sagiv-Barfi et al., 2018) участвуют антитела к ОХ40, инъецируемые в избыточном количестве в очаг опухолевого роста. Суть такой массивной атаки избытком антител может состоять в создании «эффекта неизбежности и безоговорочности» взаимодействия с рецепторами на всех типах клеток, игнорируя любые функциональные ограничения такого взаимодействия при естественном ходе волны иммунного ответа. 
Антитела представляют собой молекулу с двумя функциональными доменами: антиген-связывающий домен и Fc-фрагмент. Оба элемента молекулы антител несут функциональную нагрузку в системе противоопухолевого ответа. Этот факт требует анализа функции обоих участников терапевтического маневра. В анализе будет сделан акцент на клетки, несущие на своей мембране специфические для OX40 антител рецепторы OX40 и Fc-рецепторы.

Рецептор OX40 экспрессируется на цитоплазматической мембране CD4+, CD8+, Treg и лимфоцитах памяти. Формирование комплекca TCR/CD3, костимуляция через $\mathrm{CD} 28$, действие IL-2, IL-1, и TNF- $\alpha$ являются факторами активации, стимулирующими экспрессию OX40 на Treg и Teff. То есть в случае рассматриваемой терапии только после первичной активации ДК инъекциями $\mathrm{CpG}$, развитием гуморальной реакции и контакта экспрессирующихся на поверхности ДК кофакторных молекул с их агонистами на Т-клетках возможна последующая полная активация функций Teff. Наивные Т-клетки не экспрессируют рецептор ОX40. Только при взаимодействии с лигандом эти клетки активируют свои иммунные свойства. Время активации для Teff, согласно различным источникам, варьирует от 12 ч до 5 сут. Время такой активации для Т-клеток памяти составляет 1-4 ч.

Главным эффектом взаимодействия с лигандом (антителами к OX40 или OX40L, экспрессирующимися на различных иммунных клетках) считается индукция пролиферации Teff, несущих OX40, и длительное сохранение их жизнеспособности и функциональной активности, необходимые для дальнейшей клональной экспансии. При этом, как было сказано выше, экспрессия OX40 на Treg ингибирует их пролиферативную и функциональную активность. Нужно отметить, что формирование и функциональная активность CD8+ цитотоксических Т-лимфоцитов связаны в первую очередь с взаимодействием OX40 на CD8+ Т-клетках и OX40L на ДК. Одно из проявлений такого взаимодействия индукция экспрессии CXCR5 рецептора на $\mathrm{CD} 4+$ T-клетках, определяющая миграцию Т-лимфоцитов в сайт обработки (Redmond, Weinberg, 2007; Croft, 2010; Sagiv-Barfi et al., 2018).

OX40-рецептор экспрессируют активированные инвариантные NKT. Взаимодействие NKT с ДК сопровождается усиленной OX40/OX40L зависимой продукцией IFN- $\gamma$ этими клетками. Продукция IFN- $\gamma$ приводит к активации NK-клеток, CD8+ T-лимфоцитов и макрофагов. При этом ДК также могут секретировать IFN- $\gamma$ при реверсивной активации. Немедленно после первичного активирующего сигнала NKT экспрессируют CD137 кофакторную молекулу, необходимую для полной активации клеток и секреции цитокинов. Контроль продукции IFN- $\gamma$ NKT определяется достаточностью и силой TCR/CD1d сигнала, который, в свою очередь, зависит от эффективности представления гликолипидного эндогенного антигена в комплексе CD1d активированными макрофагами, ДК и В-лимфоцитами.

Макрофаги и MDSC, инфильтрирующие опухоль, участвуют в организации опухольассоциированной стромы на протяжении всех этапов развития опухоли. Опухоль-ассоциированные макрофаги стимулируют рост опухоли за счет секреции различных растворимых факторов: TNF, TGF $\beta$, IL-1, MMP-9, VEGF, PDGF. Супрессия иммунных клеток происходит за счет секреции макрофагами IL-10 и синтеза MDSC синтазы оксида азота и аргиназы 1. Продукция и секреция оксида азота ведет к лизису Т-клеток, а аргиназа 1 конвертирует аргинин в путрисцин 
и L-орнитин, которые являются субстратом для роста раковых клеток и ингибирования пролиферации Т-лимфоцитов. Взаимодействие активированных NKT и MDSC через CD40 лигирование приводит к редукции синтеза обоих ферментов и одновременному увеличению секреции IL-12, что снижает супрессивное влияние опухоль-ассоциированной стромы на иммунные клетки. Взаимодействие NKT с комплексом CDId/гликолипид M2 макрофагов и MDSC, инфильтрирующих опухоль, сопровождается лизисом последних, опосредованным прямой цитотоксичностью NKT (Lewis, Pollard, 2006; Medina-Echeverz et al., 2014). И, значит, NKT опосредованно, через уменьшение числа опухоль-ассоциированных макрофагов и MDSC, могут воздействовать на опухоль, что может представлять еще один механизм противоопухолевой активности NKT (Zaini et al., 2007; Акинфиева и др., 2010; Croft, 2010; Metelitsa, 2011). В дополнение к сказанному известно, что многие опухоли несут на своей поверхности CD1d и могут быть прямой мишенью для цитотоксического действия NKT (Metelitsa, 2011).

OX40-рецептор экспрессируют находящиеся в опухолевом очаге, активированные множеством кофакторов NK-клетки. Также на этих клетках экспрессируется OX40L. Как и в случае с NKT, взаимодействие активированных NK-клеток с ДК через OX40/ OX40L лигирование приводит к усиленной продукции IFN- $\gamma$ натуральными киллерами. При этом описано реверсивное взаимодействие OX40L NK-клетка/OX40 ДК. Антитела к ОХ40 являются дополнительным фактором активации NK-клеток. Наиболее важные функции активированных NK-клеток - их неспецифическая цитолитическая активность, осуществляемая в отсутствие молекул МНCI на клетках-мишенях независимо от антител и комплемента, и секреция хемокинов и цито- кинов, играющих важную роль в регуляции иммунного ответа.

NK-клетки, как и макрофаги, нейтрофилы и тучные клетки, несут Fc-рецепторы, через которые также происходит активация клетки при связывании с Fc-фрагментами антител. Возможно, что для полной активации цитолитической активности натуральных киллеров необходимо взаимодействие антител к OX40 и с OX40, и с Fc-рецептором одновременно на одной NK-клетке. Участие NK-клеток в лизисе раковых клеток может определяться ADCC-механизмом. Клетки опухоли в результате функционального взаимодействия растущей опухоли и организма покрыты антителами к поверхностным антигенам. Это позволяет NK-клеткам не специфически, через образование комплекса Fc-рецептора NK-клеток с Fc-фрагментом антител, атаковать трансформированные клетки (Croft, 2010; Абакушина и др., 2012; Murphy et al., 2014).

Treg также экспрессируют OX40рецептор. При этом взаимодействие с лигандом (антителами к OX40) ингибирует супрессивную функцию Treg (Jensen et al., 2010; Weinberg et al., 2011; Murphy et al., 2014; SagivBarfi et al., 2018).

Лигирование OX40 и/или Fc-рецепторов, экспрессирующихся нейтрофилами, с антителами к OX40 способствует повышению выживаемости нейтрофилов, связанной с редукцией экспрессии молекулярных проапоптотических факторов. Этот тип клеток, как и NK-клетки, обладает свойством лизировать клетки, покрытые антителами, через механизм ADCC. Этот факт предполагает возможность участия активированных нейтрофилов в разрушении клеток опухоли (Акинфиева и др., 2010; Brandau, 2013; Murphy et al., 2014).

Таким образом, OX40-антитела продолжают и поддерживают волну активации, на- 
чатую активированными ДК, и участвуют в запуске процесса киллинга раковых клеток через эффекторы: NK-клетки, NKT, возможно через реполяризованные макрофаги и нейтрофилы и механизмы: ADCC, перфорин/гранзим-ассоциированный лизис, лизис вследствие активации апоптоза FasL/Fas или иным, активирующим апоптотические пути взаимодействием.

После инъекций $\mathrm{CpG}$ и антител к OX40 совместно с активацией АПК и индукцией начальных этапов иммунного ответа, одним из которых служит появление, поглощение, процессинг и презентация антигена, активируются и праймируются CD8+ T-эффекторы. Специфический антигенный ответ CD8+ Т-лимфоциты могут сформировать только после взаимодействия TCR и антигена, представленного MHCII, в синергичном взаимодействии с кофакторными молекулами.

Взаимодействие наивных Т-лимфоцитов с соответствующей по специфичности антигенной детерминантой и костимулятором В7, представленными на поверхности АПК, инициирует полноценный синтез и секрецию IL-2, который аутокринным способом стимулирует наивные Т-клетки к пролиферации и дифференцировке. Завершившие дифференцировку Т-лимфоциты характеризуются усилением экспрессии на своей поверхности молекул LFA-1 и CD2, которые обеспечивают их более эффективное взаимодействие с адгезивными молекулами ICAM и LFA-3, обильно представленными на поверхности макрофагов, что необходимо для праймирования эффекторных клеток. В рамках проводимого анализа важен тот факт, что интегрины ICAM также обильно представлены на опухолевых клетках. Специфическое антиген-зависимое взаимодействие цитотоксических Т-лимфоцитов с опухолевыми клетками усиливается через дополнительное взаимо- действие LFA-1, CD2 и ICAM и служит условием проявления цитолитической активности эффекторами.

\section{Заключение}

Процессинг и презентация in situ активированными ДК исчерпывающего репертуара индивидуальных раковых антигенов множеству индивидуальных Т-лимфоцитов означают, что именно в опухолевом очаге формируется предельно возможное разнообразие Т-клеток с уникальной антигенной специфичностью. Миграция активированных Teff в периферическое русло и закрепление в паренхиме селезенки, формирование в селезенке герминативных центров, пролиферация Т-киллерных перфорин+, гранзим+ клонов и их распространение по организму составляют основу системного адаптивного иммунного ответа. Вследствие такого продолжения in situ вакцинации происходит генерализация иммунного ответа и лизис дистальных очагов опухоли.

Ниже приведена табл. 1, демонстрирующая типы клеток, на которых могут экспрессироваться OX40, его лиганд и Fс-рецептор в результате применения описываемого терапевтического подхода с использованием OX40 антител и $\mathrm{CpG}$ олигонуклеотидов.

Опухолевый очаг инфильтрируют антигенпрезентирующие ДК, опухоль-ассоциированные макрофаги, MDSC, NK-клетки, NKT, CD4+ и CD8+ Т-лимфоциты, Treg, проопухолевые гранулярные нейтрофилы, находящиеся в супрессированном состоянии вследствие гуморальной регуляции опухолевыми клетками. Проведенный анализ свидетельствует, что главным действующим стимулом при завязке иммунного ответа в очаге опухоли является экспериментально доказанное снятие инъекциями $\mathrm{CpG}$ иммунологической толерантности у клеток, инфильтрирующих опухоль, а 
Таблица 1. Типы клеток, на которых могут экспрессироваться OX40, его лиганд и Fc-рецептор в результате применения терапевтического подхода (Sagiv-Barfi et al., 2018)

Table 1. Types of cells that can express OX40, its ligand, and Fc-receptor in response to therapeutic application (Sagiv-Barfi et al., 2018)

\begin{tabular}{|l|c|c|c|}
\hline \multicolumn{1}{|c|}{ Фактор/тип клеток } & OX40 & OX40L & Fс-рецептор \\
\hline ДК & + & + & \\
Treg & + & & \\
CD8+ Т-лимфоциты & + & & + \\
CD4+ Т-лимфоциты & + & + & + \\
NK-клетки & + & + & + \\
NKT & + & & + \\
Макрофаги & + & & \\
Нейтрофилы & & & \\
\hline
\end{tabular}

именно супрессированных ДК, Т-лимфоцитов, макрофагов и MDSC. Совокупный анализ литературных данных в контексте работы (Sagiv-Barfi et al., 2018) свидетельствует о том, что совместные инъекции двух активаторов приводят к тому, что $\mathrm{CpG}$ активирует ДК, а антитела к ОХ40 являются дополнительным фактором активации NK-клеток. Натуральные киллеры немедленно приступают к лизису раковых клеток или через негативные регуляторы MHCI, или через систему стрессиндуцированных и адгезивных молекул, или через Fc-рецептор опосредованный механизм. Одновременно ДК гуморально активируют Т-хелперы 1-го типа, которые в свою очередь активируют макрофаги. Сменившие поляризацию активированные M1 макрофаги включают весь свой литический арсенал: NO, ROS, ADCC, FasL, что суммируется в усилении первоначального разрушения клеток опухоли, индуцированного NK-клетками. В процессе лизиса трансформированных клеток могут принимать участие и другие популяции инфильтрирующих опухоль клеток. Это и ДК, и опухоль-реактивные нейтрофилы, и NKT.

Гуморальный интегральный ответ можно описать следующими общими чертами.
Активированные ДК начинают продукцию и секрецию IL-12, который стимулирует продукцию IFN- $\gamma$ и IL-2. Происходит активация Т-лимфоцитов, которые активируют макрофаги. Активированные макрофаги секретируют TNF- $\alpha$, а при активном фагоцитозе индуцируется секреция IL-12, IL-1, IL-6, IL-8, IFN- $\gamma$, CSF. NK-клетки, T-лимфоциты и NKT в результате активации секретируют IFN- $\gamma$. IFN- $\gamma$ стимулирует дозревание ДК, активирует макрофаги и CD8+ T-лимфоциты. Формируется петля активации, характеризующаяся необратимостью развития иммунного ответа. Происходит активация адаптивного звена иммунитета, что необходимо для развития системного противоопухолевого иммунного ответа (5-9 сут).

Таким образом, если в локальном месте, таком как, например, первичный опухолевый очаг, одновременно присутствуют активированные ДК, макрофаги, NK-клетки, NKT, Т-хелперы 1-го типа, нейтрофилы, то может развиться интегрированный, самоподдерживающийся цитокиновым сопровождением, иммунный ответ, обусловленный клетками врожденного иммунитета. Результатом такого ответа будет первая волна опухоль-ас- 
социированных антигенов. Это приведет к активации адаптивного звена иммунного от- вета и формированию акселеративной петли активации клеток врожденного иммунитета.

\section{Благодарности / Acknowledgements}

Данная работа была выполнена при поддержке бюджетного проекта в рамках государственного задания № 0324-2019-0042-С-01 (рег. № АAАА-A17-117071240065-4) и проекта РФФИ № 18-29-09045.

The research was supported by the budget project as part of the state assignment No. 0324-20190042-C-01 (Reg. No. AAAA-A17-117071240065-4) and RFBR project No. 18-29-09045.

\section{Список литературы / References}

Абакушина Е.В., Кузьмина Е.Г., Коваленко Е.И. (2012) Основные свойства и функции NKклеток человека. Иммунология, 33(4): 220-225 [Abakushina E.V., Kuzmina E.G., Kovalenko E.I. (2012) The main characteristics of human natural killer cells. Immunology [Immunologiya], 33(4): 220-225 (in Russian)]

Акинфиева О.В., Бубнова Л.Н., Бессмельцев С.С. (2010) NКТ-клетки: характерные свойства и функциональная значимость для регуляции иммунного ответа. Онкогематология, 5(4): 39-47 [Akinfieva O.V., Bubnova L.N., Bessmeltsev S.S. (2010) NKT cells: characteristic features and functional significance in the immune response regulation. Oncohematology [Onkogematologiya], 5(4): 39-47 (in Russian)]

Бережной А.Е., Гнучев Н.В., Георгиев Г.П., Козлов А.М., Ларин С.С. (2008) Молекулярные механизмы взаимодействия опухоли и имммунной системы. Вопросы онкологии, 54(6): 669-683 [Berezhnoy A.E., Gnuchev N.V., Georgiev G.P., Kozlov A.M., Larin S.S. (2008) Molecular mechanisms of interaction between tumor and immune system. Oncology Issues [Voprosy onkologii], 54(6): 669-683 (in Russian)]

Дунаев П.Д., Бойчук С.В., Мустафин И.Г. (2012) Свойства и роль фактора некроза опухолей альфа в патогенезе ВИЧ-инфекции. Казанский медицинский журнал, 93(2): 290-293 [Dunaev P.D., Boychuk S.V., Mustafin I.G. (2012) The properties and role of tumor necrosis factor alpha in the pathogenesis of HIV infection. Kazan Medical Journal [Kazanski medicinski zhurnal], 93(2): 290-293 (in Russian)]

Зенков Н.К., Меньщикова Е.Б., Шкурупий В.А. (2007) Механизмы активации макрофагов. Успехи современной биологии, 127(3): 243-256 [Zenkov N.K., Men'shchikova E.B., Shkurupii V.A. (2007) Mechanisms of macrophage activation. Successes of Modern Biology [Uspekhi sovremennoy biologii], 127(3): 243-256 (in Russian)]

Кадагидзе 3.Г. (2003) Цитокины. Практическая онкология, 4(3): 131-139 [Kadagidze Z.G. (2003) Cytokines. Practical Oncology [Prakticheskaya onkologiya], 4(3): 131-139 (in Russian)]

Ключагина Ю.И., Соколова 3.А., Барышникова М.А. (2017) Роль рецептора PD1 и его лигандов PDL1 и PDL2 в иммунотерапии опухолей. Онкопедиатрия, 4(1): 49-55 [Klyuchagina Yu.I., Sokolova Z.A., Baryshnikova M.A. (2017) Role of PD-1 receptor and its ligands PD-L1 and PD-L2 in cancer immunotherapy. Oncopediatrics [Onkopediatriya], 4(1): 49-55 (in Russian)]

Кулаков В.В., Киселевский М.В., Полоцкий Б.Е., Пинегин Б.В. (1999) Изучение цитостатическои и цитотоксической активности нейтрофилов периферической крови нормальных доно- 
ров и больных раком легких. Вестник РОНЦ Им. Н.Н. Блохина РАМН, 10(2): $26-31$ [Kulakov V.V., Kiselevsky M.V., Polotsky B.E., Pinegin B.V. (1999) Study of cytostatic and cytotoxic activity of peripheral neutrophils from normal donors and lung cancer patients. Bulletin of N.N. Blokhin National Medical Research Center of Oncology [Vestnik RONC Im. N.N. Blokhina RAMN], 26-31 (in Russian)]

Луцкий А.А., Жирков А.А., Лобзин Д.Ю., Рао М., Алексеева Л.А., Мейрер М., Лобзин Ю.В. (2015) Интерферон- $\gamma$ : биологическая функция и значение для диагностики клеточного иммунного ответа. Журнал инфектологии, 7(4): 10-22 [Lutckii A.A., Zhirkov A.A., Lobzin D.Yu., Rao M., Alekseeva L.A., Maeurer M., Lobzin Yu.V. (2015) Interferon- $\gamma$ : biological function and application for study of cellular immune response. Journal Infectology [Zhurnal infektologii], 7(4): 10-22 (in Russian)]

Лисяный Н.И., Лисяный А.А. (2018) Нейтрофилы и онкогенез. Клиническая онкология, 8(1): 40-45 [Lisyaniy M.I., Lisyaniy A.O. (2018) Neutrophils and oncogenesis. Clinical Oncology [Klinicheskaya onkologiya], 8(1): 40-45 (in Russian)]

Майборода А.А. (2013) Апоптоз - гены и белки. Сибирский медицинский журнал (Иркутск), 118(3): 130-135 [Majboroda A.A. (2013) Apoptosis - genes and proteins. Siberian Medical Journal (Irkutsk) [Sibirskiy meditsinskiy zhurnal (Irkutsk)], 28(3): 130-135 (in Russian)]

Мальцева В.Н., Сафронова В.Г. (2009) Неоднозначность роли нейтрофила в генезе опухоли. Цитология, 51(6): 467-474 [Maltseva V.N., Safronova V.G. (2009) Ambiguity role of neutrophils in oncogenesis. Cytology [Tsitologiya], 51(6): 467-474 (in Russian)]

Манских В.Н. (2007) Пути гибели клетки и их биологическое значение. Цитология, 49(11): 909-915 [Manskikh V.N. (2007) Pathways of cell death and their biological importance. Cytology [Tsitologiya], 49(11): 909-915 (in Russian)]

Мисюрин В.А. (2015) Структура и свойства основных рецепторов и лигандов внешнего пути апоптоза. Российский биотерапевтический журнал, 14(2): 23-30 [Misyurin V.A. (2015) Structure and functions of main apoptosis receptors and ligands. Russian Journal of Biotherapy [Rossiiskii bioterapevticheskii zhurnal], 14(2): 23-30 (in Russian)]

Монастырская Е.А., Лямина С.В., Малышев И.Ю. (2008) М1 и М2 фенотипы активированных макрофагов и их роль в иммунном ответе и патологии. Патогенез, 6(4): 31-39 [Monastyrskaya E.A., Lyamina S.V., Malyshev I.Yu. (2008) M1 and M2 phenotypes of activated macrophages and their role in immune response and pathology. Pathogenesis [Patogenez], 6(4): 31-39 (in Russian)]

Никонова А.А., Хаитов М.Р., Хаитов Р.М. (2017) Характеристика и роль различных популяций макрофагов в патогенезе острых и хронических заболеваний легких. Медицинская иммунология, 19(6): 657-672 [Nikonova A.A., Khaitov M.R., Khaitov R.M. (2017) Characteristics and role of macrophages in pathogenesis of acute and chronic lung diseases. Medical Immunology [Meditsinskaya immunologiya], 19(6): 657-672 (in Russian)]

Останин А.А., Кирикович С.С., Долгова Е.В., Проскурина А.С., Черных Е.Р., Богачев С.С. (2019) Тернистый путь макрофаг-активирующего фактора (GcMAF): от открытия к клинической практике. Вавиловский журнал генетики и селекции, 23(5): 624-631 [Ostanin A.A., Kirikovich S.S., Dolgova E.V., Proskurina A.S., Chernykh E.R., Bogachev S.S. (2019) A thorny pathway of macrophage activating factor (GcMAF): from bench to bedside. Vavilov Journal of Genetics and Breeding [Vavilovskii zhurnal genetiki i selektsii], 23(5): 624-631 (in Russian)]

$$
-259-
$$


Саяпина М.С. (2017) Иммунорегуляторные функции ингибиторов PD-1/PD-L1 и развитие к ним резистентности. Злокачественные опухоли, 7(2): 94-99 [Sayapina M.S. (2017) Immunoregulatory functions of PD-1 / PD-L1 inhibitors and development of resistance to them. Malignant Tumors [Zlokachestvennye opukholi], 7(2): 94-99 (in Russian)]

Серебренникова С.Н., Семинский И.Ж. (2008) Роль цитокинов в воспалительном процессе (сообщение 2). Сибирский медицинский журнал (Иркутск), 83(8): 5-8 [Serebrennikova S., Seminsky I. (2008) The role of cytokines in the inflammatory process (part 2). Siberian Medical Journal (Irkutsk) [Sibirskiy meditsinskiy zhurnal (Irkutsk)], 83(8): 5-8 (in Russian)]

Талаев В.Ю., Плеханова М.В. (2014) Исследование миграции дендритных клеток и трафика антигенов в целях совершенствования средств иммунопрофилактики. Медиаль, 2: 154-171 [Talayev V.Yu., Plechanova M.V. (2014) Investigation of the dendritic cell migration and the anigen traffic for perfecting of immunoprofilaxis agents. Medial [Medial'], 2: 154-171 (in Russian)]

Уткин О.В., Новиков В.В. (2012) Рецепторы смерти в модуляции апоптоза. Успехи современной биологии, 132(4): 381-390 [Utkin O.V., Novikov V.V. (2012) Death receptors in modulation of apoptosis. Successes of Modern Biology [Uspekhi sovremennoy biologii], 132(4): 381-390 (in Russian)]

Чердынцева Н.В., Митрофанова И.В., Булдаков М.А., Стахеева М.Н., Патышева М.Р., Завьялова М.В., Кжышковска Ю.Г. (2017) Макрофаги и опухолевая прогрессия: на пути к макрофаг-специфичной терапии. Бюллетень сибирской медицины, 16(4): 61-74 [Cherdyntseva N.V., Mitrofanova I.V., Buldakov M.A., Stakheeva M.N., Patysheva M.R., Zavjalova M.V., Kzhyshkowska J.G. (2017) Macrophages and tumor progression: on the way to macrophage-specific therapy. Bulletin of Siberian Medicine [Byulleten' sibirskoi meditsiny], 16(4): 61-74 (in Russian)]

Aggarwal B.B. (2003) Signalling pathways of the TNF superfamily: a double-edged sword. Nature Reviews Immunology, 3(9): 745-756

Akira S. (2000) The role of IL-18 in innate immunity. Current Opinion in Immunology, 12(1): $59-63$

Alyamkina E.A., Leplina O.Y., Sakhno L.V., Chernykh E.R., Ostanin A.A., Efremov Y.R., Shilov A.G., Proskurina A.S., Orishchenko K.E., Dolgova E.V., Rogachev V.A., Nikolin V.P.,Popova N.A., Zagrebelniy S.N., Bogachev S.S., Shurdov M.A. (2010) Effect of double-stranded DNA on maturation of dendritic cells in vitro. Cellular Immunology, 266(1): 46-51

Alyamkina E.A., Leplina O.Y., Ostanin A.A., Chernykh E.R., Nikolin V.P., Popova N.A., Proskurina A.S., Gvozdeva T.S., Dolgova E.V., Orishchenko K.E., Rogachev V.A., Sidorov S.V., Varaksin N.A., Ryabicheva T.G., Bogachev S.S., Shurdov M.A. (2012) Effects of human exogenous DNA on production of perforin-containing CD8+ cytotoxic lymphocytes in laboratory setting and clinical practice. Cellular Immunology, 276(1-2): 59-66

Atretkhany K.-S.N., Drutskaya M.S. (2016) Myeloid-derived suppressor cells and proinflammatory cytokines as targets for cancer therapy. Biochemistry-Moscow, 81(11): 1274-1283

Aznar M.A., Tinari N., Rullán A.J., Sánchez-Paulete A.R., Rodriguez-Ruiz M.E., Melero I. (2017) Intratumoral delivery of immunotherapy - act locally, think globally. Journal of Immunology, 198(1): 31-39

Bauer S., Groh V., Wu J., Steinle A., Phillips J.H., Lanier L.L., Spies T. (1999) Activation of NK cells and T cells by NKG2D, a receptor for stress-inducible MICA. Science, 285(5428): 727-729 
Behar S.M., Cardell S. (2000) Diverse CD1d-restricted T cells: diverse phenotypes, and diverse functions. Seminars in Immunology, 12(6): 551-560

Bendelac A., Savage P.B., Teyton L. (2007) The biology of NKT cells. Annual Review of Immunology, 25: 297-336

Biassoni R. (2009) Human natural killer receptors, co-receptors, and their ligands. Current Protocols in Immunology, 84(1): 14.10.1-14.10.40

Biassoni R., Cantoni C., Marras D., Giron-Michel J., Falco M., Moretta L., Dimasi N. (2003) Human natural killer cell receptors: insights into their molecular function and structure. Journal of Cellular and Molecular Medicine, 7(4): 376-387

Billiau A., Matthys P. (2009) Interferon- $\gamma$ : A historical perspective. Cytokine \& Growth Factor Reviews, 20(2): 97-113

Bilusic M., Gulley J.L. (2017) Local immunotherapy: a way to convert tumors from "cold" to "hot". JNCI: Journal of the National Cancer Institute, 109(12): djx132

Bjorkstrom N.K., Riese P., Heuts F., Andersson S., Fauriat C., Ivarsson M.A., Björklund A.T., Flodström-Tullberg M., Michaëlsson J., Rottenberg M.E., Guzmán C.A., Ljunggren H.G., Malmberg K.-J. (2010) Expression patterns of NKG2A, KIR, and CD57 define a process of CD56dim NK-cell differentiation uncoupled from NK-cell education. Blood, 116(19): 3853-3864

Bottino C., Castriconi R., Moretta L., Moretta A. (2005) Cellular ligands of activating NK receptors. Trends in Immunology, 26(4): 221-226

Boyman O., Sprent J. (2012) The role of interleukin-2 during homeostasis and activation of the immune system. Nature Reviews Immunology, 12(3): 180-190

Brandau S. (2013) The dichotomy of neutrophil granulocytes in cancer. Seminars in Cancer Biology, 23(3): 139-140

Brunner C., Seiderer J., Schlamp A., Bidlingmaier M., Eigler A., Haimerl W., Lehr H.A., Krieg A.M., Hartmann G., Endres S. (2000) Enhanced dendritic cell maturation by TNF-alpha or cytidine-phosphate-guanosine DNA drives $\mathrm{T}$ cell activation in vitro and therapeutic anti-tumor immune responses in vivo. Journal of Immunology, 165(11): 6278-6286

Bryceson Y.T., Pende D., Maul-Pavicic A., Gilmour K.C., Ufheil H., Vraetz T., Chiang S.C., Marcenaro S., Meazza R., Bondzio I., Walshe D., Janka G., Lehmberg K., Beutel K., zur Stadt U., Binder N., Arico M., Moretta L., Henter J.I., Ehl S. (2012) A prospective evaluation of degranulation assays in the rapid diagnosis of familial hemophagocytic syndromes. Blood, 119(12): 2754-2763

Buelens C., Verhasselt V., De Groote D., Thielemans K., Goldman M., Willems F. (1997) Human dendritic cell responses to lipopolysaccharide and CD40 ligation are differentially regulated by interleukin-10. European Journal of Immunology, 27(8): 1848-1852

Caligiuri M.A. (2008) Human natural killer cells. Blood, 112(3), 461-469

Chakrabandhu K., Huault S., Garmy N., Fantini J., Stebe E., Mailfert S., Marguet D., Hueber A.-O. (2008) The extracellular glycosphingolipid-binding motif of Fas defines its internalization route, mode and outcome of signals upon activation by ligand. Cell Death \& Differentiation, 15(12): 1824-1837

Chung B., Aoukaty A., Dutz J., Terhorst C., Tan R. (2005) Signaling lymphocytic activation molecule-associated protein controls NKT cell functions. Journal of Immunology, 174(6): 3153-3157

Cooper M.A., Fehniger T.A., Caligiuri M.A. (2001) The biology of human natural killer-cell subsets. Trends in Immunology, 22(11): 633-640 
Corzo C.A., Condamine T., Lu L., Cotter M.J., Youn J.-I., Cheng P., Cho H.I., Celis E., Quiceno D.G., Padhya T., McCaffrey T.V., McCaffrey J.C., Gabrilovich D.I. (2010) HIF-1 $\alpha$ regulates function and differentiation of myeloid-derived suppressor cells in the tumor microenvironment. Journal of Experimental Medicine, 207(11): 2439-2453

Croft M. (2010) Control of immunity by the TNFR-related molecule OX40 (CD134). Annual Review of Immunology, 28: 57-78

Dajon M., Iribarren K., Cremer I. (2017) Toll-like receptor stimulation in cancer: A pro- and antitumor double-edged sword. Immunobiology, 222(1): 89-100

Dallegri F., Ottonello L., Ballestrero A., Dapino P., Ferrando F., Patrone F., Sacchetti C. (1991) Tumor cell lysis by activated human neutrophils: analysis of neutrophil-delivered oxidative attack and role of leukocyte function-associated antigen 1. Inflammation, 15(1): 15-30

De Larco J.E., Wuertz B.R.K., Furcht L.T. (2004) The potential role of neutrophils in promoting the metastatic phenotype of tumors releasing interleukin-8. Clinical Cancer Research, 10(15): 48954900

Del Vecchio M., Bajetta E., Canova S., Lotze M.T., Wesa A., Parmiani G., Anichini A. (2007) Interleukin-12: biological properties and clinical application. Clinical Cancer Research, 13(16): 46774685

Dennehy K.M., Klimosch S.N., Steinle A. (2011) Cutting edge: NKp80 uses an atypical hemiITAM to trigger NK cytotoxicity. Journal of Immunology, 186(2): 657-661

Di Carlo E., Forni G., Lollini P., Colombo M.P., Modesti A., Musiani P. (2001) The intriguing role of polymorphonuclear neutrophils in antitumor reactions. Blood, 97(2): 339-345

Diamond M.S., Staunton D.E., Marlin S.D., Springer T.A. (1991) Binding of the integrin Mac-1 (CD11b/CD18) to the third immunoglobulin-like domain of ICAM-1 (CD54) and its regulation by glycosylation. Cell, 65(6): 961-971

Dollins C.M., Nair S., Boczkowski D., Lee J., Layzer J.M., Gilboa E., Sullenger B.A. (2008) Assembling OX40 aptamers on a molecular scaffold to create a receptor-activating aptamer. Chemistry \& Biology, 15(7): 675-682

Dong H., Strome S.E., Salomao D.R., Tamura H., Hirano F., Flies D.B., Roche P.C., Lu J., Zhu G., Tamada K., Lennon V.A., Celis E., Chen L. (2002) Tumor-associated B7-H1 promotes T-cell apoptosis: a potential mechanism of immune evasion. Nature Medicine, 8(8): 793-800

East J.E., Kennedy A.J., Webb T.J. (2014) Raising the roof: the preferential pharmacological stimulation of Th1 and Th2 responses mediated by NKT cells. Medicinal Research Reviews, 34(1): $45-76$

Falschlehner C., Ganten T.M., Koschny R., SchaeferU., Walczak H. (2009) TRAIL and other TRAIL receptor agonists as novel cancer therapeutics. Therapeutic targets of the TNF superfamily. Advances in experimental medicine and biology. Vol 647. Grewal I.S. (ed.) Springer, New York, NY, p. 195-206

Fanger N.A., Maliszewski C.R., Schooley K., Griffith T.S. (1999) Human dendritic cells mediate cellular apoptosis via tumor necrosis factor-related apoptosis-inducing ligand (TRAIL). Journal of Experimental Medicine, 190(8): 1155-1164

Farkona S., Diamandis E.P., Blasutig I.M. (2016) Cancer immunotherapy: the beginning of the end of cancer? BMC Medicine, 14: 73

Gabrilovich D.I. (2017) Myeloid-derived suppressor cells. Cancer Immunology Research, 5(1): 3-8 
Girardi M., Oppenheim D.E., Steele C.R., Lewis J.M., Glusac E., Filler R., Hobby P., Sutton B., Tigelaar R.E., Hayday A.C. (2001) Regulation of cutaneous malignancy by gamma delta T cells. Science, 294(5542): 605-609

Godfrey D.I., Kronenberg M. (2004) Going both ways: Immune regulation via CD1ddependent NKT cells. Journal of Clinical Investigation, 114(10): 1379-1388

Gómez Román V.R., Murray J.C., Weiner L.M. (2014) Antibody-dependent cellular cytotoxicity (ADCC). Antibody Fc. Ackerman M.E., Nimmerjahn F. (Eds.) Academic Press, p. 1-27

Greilberger J., Herwig R. (2020) Vitamin D - deglycosylated vitamin D binding protein dimer: positive synergistic effects on recognition, activation, phagocytosis and oxidative stress on macrophages. Clinical Laboratory, 66(1-2): 169-177

Groh V., Rhinehart R., Secrist H., Bauer S., Grabstein K.H., Spies T. (1999) Broad tumorassociated expression and recognition by tumor-derived gamma delta T cells of MICA and MICB. Proceedings of the National Academy of Sciences of the United States of America, 96(12): 68796884

Guiducci C., Vicari A.P., Sangaletti S., Trinchieri G., Colombo M.P. (2005) Redirecting in vivo elicited tumor infiltrating macrophages and dendritic cells towards tumor rejection. Cancer Research, 65(8): 3437-3446

Hammerich L., Binder A., Brody J.D. (2015) In situ vaccination: Cancer immunotherapy both personalized and off-the-shelf. Molecular Oncology, 9(10): 1966-1981

Hammerich L., Bhardwaj N., Kohrt H.E., Brody J.D. (2016) In situ vaccination for the treatment of cancer. Immunotherapy, 8(3): 315-330

Hamza T., Barnett J.B., Li B. (2010) Interleukin 12 a key immunoregulatory cytokine in infection applications. International Journal of Molecular Sciences, 11(3): 789-806

Hira S.K., Mondal I., Bhattacharya D., Manna P.P. (2014) Downregulation of endogenous STAT3 augments tumoricidal activity of interleukin 15 activated dendritic cell against lymphoma and leukemia via TRAIL. Experimental Cell Research, 327(2): 192-208

Homma S., Yamamoto N. (1990) Activation process of macrophages after in vitro treatment of mouse lymphocytes with dodecylglycerol. Clinical and Experimental Immunology, 79(2): 307-313

Igney F.H., Behrens C.K., Krammer P.H. (2005) CD95L mediates tumor counterattack in vitro but induces neutrophil-independent tumor rejection in vivo. International Journal of Cancer, 113(1): $78-87$

Ito M., Maruyama T., Saito N., Koganei S., Yamamoto K., Matsumoto N. (2006) Killer cell lectinlike receptor G1 binds three members of the classical cadherin family to inhibit NK cell cytotoxicity. Journal of Experimental Medicine, 203(2): 289-295

Jabłońska E., Puzewska W., Marcińczyk M., Grabowska Z., Jabłoński J. (2005) iNOS expression and NO production by neutrophils in cancer patients. Archivum Immunologiae et Therapiae Experimentalis, 53(2): 175-179

Jamieson A.M., Diefenbach A., McMahon C.W., Xiong N., Carlyle J.R., Raulet D.H. (2002) The role of the NKG2D immunoreceptor in immune cell activation and natural killing. Immunity, 17(1): $19-29$

Jamil K.M., Khakoo S.I. (2011) KIR/HLA interactions and pathogen immunity. Journal of Biomedicine \& Biotechnology, 2011: 298348 
Janjic B.M., Lu G., Pimenov A., Whiteside T.L., Storkus W.J., Vujanovic N.L. (2002) Innate direct anticancer effector function of human immature dendritic cells. I. Involvement of an apoptosisinducing pathway. Journal of Immunology, 168(4): 1823-1830

Janssen O., Qian J., Linkermann A., Kabelitz D. (2003) CD95 ligand - death factor and costimulatory molecule? Cell Death \& Differentiation, 10(11): 1215-1225

Jensen S.M., Maston L.D., Gough M.J., Ruby C.E., Redmond W.L., Crittenden M., Li Y., Puri S., Poehlein C.H., Morris N., Kovacsovics-Bankowski M., Moudgil T., Twitty C., Walker E.B., Hu H.M., Urba W.J., Weinberg A.D., Curti B., Fox B.A. (2010) Signaling through OX40 enhances antitumor immunity. Seminars in Oncology, 37(5): 524-532

Klebanoff S.J. (1999) Myeloperoxidase. Proceedings of the Association of American Physicians, 111(5): 383-389

Knaapen A.M., Güngör N., Schins R.P.F., Borm P.J.A., Van Schooten F.J. (2006) Neutrophils and respiratory tract DNA damage and mutagenesis: a review. Mutagenesis, 21(4): 225-236

Kohlhaas S.L., Craxton A., Sun X.-M., Pinkoski M.J., Cohen G.M. (2007) Receptor-mediated endocytosis is not required for tumor necrosis factor-related apoptosis-inducing ligand (TRAIL)induced apoptosis. Journal of Biological Chemistry, 282(17): 12831-12841

Kottschade L., Brys A., Peikert T., Ryder M., Raffals L., Brewer J., Mosca P., Markovic S. (2016) A multidisciplinary approach to toxicity management of modern immune checkpoint inhibitors in cancer therapy. Melanoma Research, 26(5): 469-480

Kovalenko E.I., Abakushina E., Telford W., Kapoor V., Korchagina E., Khaidukov S., Molotkovskaya I., Sapozhnikov A., Vlaskin P., Bovin N. (2007) Clustered carbohydrates as a target for natural killer cells: a model system. Histochemistry and Cell Biology, 127(3): 313-326

Krieg A.M. (2003) CpG motifs: the active ingredient in bacterial extracts? Nature Medicine, 9(7): $831-835$

Krutzik P.O., Nolan G.P. (2006) Fluorescent cell barcoding in flow cytometry allows highthroughput drug screening and signaling profiling. Nature Methods, 3(5): 361-368

Kumar V., Cheng P., Condamine T., Mony S., Languino L.R., McCaffrey J.C., Hockstein N., Guarino M., Masters G., Penman E., Denstman F., Xu X., Altieri D.C., Du H., Yan C., Gabrilovich D.I. (2016) CD45 phosphatase inhibits STAT3 transcription factor activity in myeloid cells and promotes tumor-associated macrophage differentiation. Immunity, 44(2): $303-315$

LaCasse C.J., Janikashvili N., Larmonier C.B., Alizadeh D., Hanke N., Kartchner J., Situ E., Centuori S., Har-Noy M., Bonnotte B., Katsanis E., Larmonier N. (2011) Th-1 lymphocytes induce dendritic cell tumor killing activity by an IFN-dependent mechanism. Journal of Immunology, 187(12): 6310-6317

Le Dréan E., Vély F., Olcese L., Cambiaggi A., Guia S., Krystal G., Gervois N., Moretta A., Jotereau F., Vivier E. (1998) Inhibition of antigen-induced T cell response and antibody-induced NK cell cytotoxicity by NKG2A: association of NKG2A with SHP-1 and SHP-2 protein-tyrosine phosphatases. European Journal of Immunology, 28(1): 264-276

Le Poole I.C., ElMasri W.M., Denman C.J., Kroll T.M., Bommiasamy H., Lyons Eiben G., Kast W.M. (2008) Langerhans cells and dendritic cells are cytotoxic towards HPV16 E6 and E7 expressing target cells. Cancer Immunology, Immunotherapy, 57(6): 789-797 
Leifer C.A., Medvedev A.E. (2016) Molecular mechanisms of regulation of Toll-like receptor signaling. Journal of Leukocyte Biology, 100(5): 927-941

Lewis C.E., Pollard J.W. (2006) Distinct role of macrophages in different tumor microenvironments. Cancer Research, 66(2): 605-612

Li B. (2015) Advances in studies related to interleukin-12 family and infectious diseases. Infection International, 4(2): 35-39

Li H., Han Y., Guo Q., Zhang M., Cao X. (2009) Cancer-expanded myeloid-derived suppressor cells induce anergy of NK cells through membrane-bound TGF-beta 1. Journal of Immunology, 182(1): $240-249$

Lichtenstein A.K., Ganz T., Selsted M.E., Lehrer R.I. (1988) Synergistic cytolysis mediated by hydrogen peroxide combined with peptide defensins. Cellular Immunology, 114(1): 104-116

Liu J., Hamrouni A., Wolowiec D., Coiteux V., Kuliczkowski K., Hetuin D., Saudemont A., Quesnel B. (2007) Plasma cells from multiple myeloma patients express B7-H1 (PD-L1) and increase expression after stimulation with IFN- $\gamma$ and TLR ligands via a MyD88-, TRAF6-, and MEK-dependent pathway. Blood, 110(1): 296-304

Ljunggren H.G., Kärre K. (1990) In search of the "missing self": MHC molecules and NK cell recognition. Immunology Today, 11(7): 237-244

Long E.O. (2008) Negative signaling by inhibitory receptors: the NK cell paradigm. Immunological Reviews, 224(1): 70-84

Lu G., Janjic B.M., Janjic J., Whiteside T.L., Storkus W.J., Vujanovic N.L. (2002) Innate direct anticancer effector function of human immature dendritic cells. II. Role of TNF, lymphotoxin-alpha(1) beta(2), Fas ligand, and TNF-related apoptosis-inducing ligand. Journal of Immunology, 168(4): 18311839

Malek T.R. (2008) The biology of interleukin-2. Annual Review of Immunology, 26: 453-479

Marabelle A., Tselikas L., de Baere T., Houot R. (2017) Intratumoral immunotherapy: using the tumor as the remedy. Annals of Oncology, 28(suppl_12): xii33-xii43

Martinez F.O., Helming L., Gordon S. (2009) Alternative activation of macrophages: an immunologic functional perspective. Annual Review of Immunology, 27: 451-483

Matsui T., Connolly J.E., Michnevitz M., Chaussabel D., Yu C.-I., Glaser C., Tindle S., Pypaert M., Freitas H., Piqueras B., Banchereau J., Palucka A.K. (2009) CD2 distinguishes two subsets of human plasmacytoid dendritic cells with distinct phenotype and functions. Journal of Immunology, 182(11): $6815-6823$

Medina-Echeverz J., Aranda F., Berraondo P. (2014) Myeloid-derived cells are key targets of tumor immunotherapy. OncoImmunology, 3(4): e28398

Melero I., Shuford W.W., Newby S.A., Aruffo A., Ledbetter J.A., Hellström K.E., Mittler R.S., Chen L. (1997) Monoclonal antibodies against the 4-1BB T-cell activation molecule eradicate established tumors. Nature Medicine, 3(6): 682-685

Melero I., Bach N., Hellström K.E., Aruffo A., Mittler R.S., Chen L. (1998) Amplification of tumor immunity by gene transfer of the co-stimulatory 4-1BB ligand: synergy with the CD28 costimulatory pathway. European Journal of Immunology, 28(3): 1116-1121

Metelitsa L.S. (2011) Anti-tumor potential of type-I NKT cells against CD1d-positive and CD1dnegative tumors in humans. Clinical Immunology, 140(2): 119-129 
Murphy K.A., Erickson J.R., Johnson C.S., Seiler C.E., Bedi J., Hu P., Pluhar G.E., Epstein A.L., Ohlfest J.R. (2014) CD8+ T cell-independent tumor regression induced by Fc-OX40L and therapeutic vaccination in a mouse model of glioma. Journal of Immunology, 192(1): 224-233

Murthy V., Minehart J., Sterman D.H. (2017) Local immunotherapy of cancer: innovative approaches to harnessing tumor-specific immune responses. Journal of the National Cancer Institute, 109(12): djx097

Ngwenya B.Z., Yamamoto N. (1985) Activation of peritoneal macrophages by lysophosphatidylcholine. Biochimica et Biophysica Acta, 839(1): 9-15

Ngwenya B.Z., Yamamoto N. (1986) Effects of inflammation products on immune systems. Lysophosphatidylcholine stimulates macrophages. Cancer Immunology, Immunotherapy, 21(3): 174-182

Nozari A., Berezovski M.V. (2017) Aptamers for CD antigens: from cell profiling to activity modulation. Molecular Therapy - Nucleic Acids, 6: 29-44

Olmos G., Lladó J. (2014) Tumor necrosis factor alpha: a link between neuroinflammation and excitotoxicity. Mediators of Inflammation, 2014: 861231

Pan X.-Q. (2012) The mechanism of the anticancer function of M1 macrophages and their use in the clinic. Chinese Journal of Cancer, 31(12): 557-563

Peipp M., van Bueren J.J.L., Schneider-Merck T., Bleeker W.W.K., Dechant M., Beyer T., Repp R., van Berkel P.H.C, Vink T., van de Winkel J.G.J., Parren P.W.H.I., Valerius T. (2008) Antibody fucosylation differentially impacts cytotoxicity mediated by NK and PMN effector cells. Blood, 112(6): 2390-2399

Pericle F., Kirken R.A., Epling-Burnette P.K., Blanchard D.K., Djeu J.Y. (1996) Direct killing of interleukin-2-transfected tumor cells by human neutrophils. International Journal of Cancer, 66(3): 367-373

Peter M.E., Krammer P.H. (2003) The CD95(APO-1/Fas) DISC and beyond. Cell Death \& Differentiation, 10(1): 26-35

Petty A.J., Yang Y. (2017) Tumor-associated macrophages: Implications in cancer immunotherapy. Immunotherapy, 9(3): 289-302

Philchenkov A.A. (2003) Caspases as regulators of apoptosis and other cell functions. Biochemistry (Moscow), 68(4): 365-376

Piontek G.E., Taniguchi K., Ljunggren H.G., Grönberg A., Kiessling R., Klein G., Kärre K. (1985) YAC-1 MHC class I variants reveal an association between decreased NK sensitivity and increased H-2 expression after interferon treatment or in vivo passage. Journal of Immunology, 135(6): $4281-4288$

Pratico E.D., Sullenger B.A., Nair S.K. (2013) Identification and characterization of an agonistic aptamer against the T cell costimulatory receptor, OX40. Nucleic Acid Therapeutics, 23(1): 35-43

Redmond W.L., Weinberg A.D. (2007) Targeting OX40 and OX40L for the treatment of autoimmunity and cancer. Critical Reviews in Immunology, 27(5): 415-436

Sagiv-Barfi I., Czerwinski D.K., Levy S., Alam I.S., Mayer A.T., Gambhir S.S., Levy R. (2018) Eradication of spontaneous malignancy by local immunotherapy. Science Translational Medicine, 10(426): eaan4488

Schneider-Merck T., van Bueren J.J.L., Berger S., Rossen K., van Berkel P.H.C., Derer S., Beyer T., Lohse S., Bleeker W.K., Peipp M., Parren P.W.H.I., van de Winkel J.G.J., Valerius T., Dechant M. 
(2010) Human IgG2 antibodies against epidermal growth factor receptor effectively trigger antibodydependent cellular cytotoxicity but, in contrast to IgG1, only by cells of myeloid lineage. Journal of Immunology, 184(1): 512-520

Schroder K., Hertzog P.J., Ravasi T., Hume D.A. (2004) Interferon-gamma: an overview of signals, mechanisms and functions. Journal of Leukocyte Biology, 75(2): 163-189

Segal A.W. (2005) How neutrophils kill microbes. Annual Review of Immunology, 23: 197-223

Sersa G., Teissie J., Cemazar M., Signori E., Kamensek U., Marshall G., Miklavcic D. (2015) Electrochemotherapy of tumors as in situ vaccination boosted by immunogene electrotransfer. Cancer Immunology, Immunotherapy, 64(10): 1315-1327

Sgambato A., Casaluce F., Sacco P.C., Palazzolo G., Maione P., Rossi A., Ciardiello F., Gridelli C. (2016) Anti PD-1 and PDL-1 immunotherapy in the treatment of advanced non- small cell lung cancer (NSCLC): a review on toxicity profile and its management. Current Drug Safety, 11(1): 62-68

Sköld M., Behar S.M. (2003) Role of CD1d-restricted NKT cells in microbial immunity. Infection and Immunity, 71(10): 5447-5455

Smyth M.J., Godfrey D.I. (2000) NKT cells and tumor immunity - a double-edged sword. Nature Immunology, 1(6): 459-460

Song Y., Margolles-Clark E., Bayer A., Buchwald P. (2014) Small-molecule modulators of the OX40-OX40 ligand co-stimulatory protein-protein interaction. British Journal of Pharmacology, 171(21): 4955-4969

Stary G., Bangert C., Tauber M., Strohal R., Kopp T., Stingl G. (2007) Tumoricidal activity of TLR7/8-activated inflammatory dendritic cells. Journal of Experimental Medicine, 204(6): 14411451

Stary G., Klein I., Kohlhofer S., Koszik F., Scherzer T., Mullauer L., Quendler H., Kohrgruber N., Stingl G. (2009) Plasmacytoid dendritic cells express TRAIL and induce CD4+ T-cell apoptosis in HIV-1 viremic patients. Blood, 114(18): 3854-3863

Street S.E.A., Cretney E., Smyth M.J. (2001) Perforin and interferon-gamma activities independently control tumor initiation, growth, and metastasis. Blood, 97(1): 192-197

Subrahmanyam P.B., Carey G.B., Webb T.J. (2014) Bcl-xL regulates CD1d-mediated antigen presentation to NKT cells by altering CD1d trafficking through the endocytic pathway. Journal of Immunology, 193(5): 2096-2105

Takahashi Y., Matsutani N., Nakayama T., Dejima H., Uehara H., Kawamura M. (2017) Immunological effect of local ablation combined with immunotherapy on solid malignancies. Chinese Journal of Cancer, 36: 49

Tang X., Li Q., Zhu Y., Zheng D., Dai J., Ni W., Wei J., Xue Y., Chen K., Hou W., Zhang C., Feng X., Liang Y. (2015) The advantages of PD1 activating chimeric receptor (PD1-ACR) engineered lymphocytes for PDL1(+) cancer therapy. American Journal of Translational Research, 7(3): 460-473

Thiery J., Keefe D., Boulant S., Boucrot E., Walch M., Martinvalet D., Goping I.S., Bleackley R.C., Kirchhausen T., Lieberman J. (2011) Perforin pores in the endosomal membrane trigger the release of endocytosed granzyme B into the cytosol of target cells. Nature Immunology, 12(8): 770-777

Trinchieri G. (2003) Interleukin-12 and the regulation of innate resistance and adaptive immunity. Nature Reviews Immunology, 3(2): 133-146

$$
-267-
$$


Tyrinova T.V., Leplina O.Y., Mishinov S.V., Tikhonova M.A., Shevela E.Y., Stupak V.V., Pendyurin I.V., Shilov A.G., Alyamkina E.A., Rubtsova N.V., Bogachev S.S., Ostanin A.A., Chernykh E.R. (2013) Cytotoxic activity of ex-vivo generated IFN $\alpha$-induced monocyte-derived dendritic cells in brain glioma patients. Cellular Immunology, 284(1-2): 146-153

van Dommelen S.L.H., Degli-Esposti M.A. (2004) NKT cells and viral immunity. Immunology and Cell Biology, 82(3): 332-341

Vanderheyde N., Aksoy E., Amraoui Z., Vandenabeele P., Goldman M., Willems F. (2001) Tumoricidal activity of monocyte-derived dendritic cells: evidence for a caspase-8-dependent, Fasassociated death domain-independent mechanism. Journal of Immunology, 167(7): 3565-3569

Vicari A.P., Chiodoni C., Vaure C., Aït-Yahia S., Dercamp C., Matsos F., Reynard O., Taverne C., Merle P., Colombo M.P., O’Garra A., Trinchieri G., Caux C. (2002) Reversal of tumor-induced dendritic cell paralysis by $\mathrm{CpG}$ immunostimulatory oligonucleotide and anti-interleukin 10 receptor antibody. Journal of Experimental Medicine, 196(4): 541-549

Wajant H., Pfizenmaier K., Scheurich P. (2003) Tumor necrosis factor signaling. Cell Death \& Differentiation, 10(1): 45-65

Wang L., Yang J.K., Kabaleeswaran V., Rice A.J., Cruz A.C., Park A.Y., Yin Q., Damko E., Jang S.B., Raunser S., Robinson C.V., Siegel R.M., Walz T., Wu H. (2010) The Fas-FADD death domain complex structure reveals the basis of DISC assembly and disease mutations. Nature Structural \& Molecular Biology, 17(11): 1324-1329

Wang W., Erbe A.K., Hank J.A., Morris Z.S., Sondel P.M. (2015) NK cell-mediated antibodydependent cellular cytotoxicity in cancer immunotherapy. Frontiers in Immunology, 6: 368

Webb T.J., Carey G.B., East J.E., Sun W., Bollino D.R., Kimball A.S., Brutkiewicz R.R. (2016) Alterations in cellular metabolism modulate CD1d-mediated NKT-cell responses. Pathogens and Disease, 74(6): ftw055

Weinberg A.D., Morris N.P., Kovacsovics-Bankowski M., Urba W.J., Curti B.D. (2011) Science gone translational: the OX40 agonist story. Immunological Reviews, 244(1): 218-231

Wu H., Hymowitz S.G. (2010) Structure and function of tumor necrosis factor (TNF) at the cell surface. Handbook of Cell Signaling. Bradshaw R., Dennis E. (eds.) Academic Press, p. 265-275

Yamamoto N., Ngwenya B.Z. (1987) Activation of mouse peritoneal macrophages by lysophospholipids and ether derivatives of neutral lipids and phospholipids. Cancer Research, 47(8): 2008-2013

Yamamoto N., Kumashiro R. (1993) Conversion of vitamin D3 binding protein (group-specific component) to a macrophage activating factor by the stepwise action of beta-galactosidase of $\mathrm{B}$ cells and sialidase of T cells. Journal of Immunology, 151(5): 2794-2802

Yamamoto N., Suyama H., Yamamoto N. (2008) Immunotherapy for prostate cancer with Gc protein-derived macrophage-activating factor, GcMAF. Translational Oncology, 1(2): 65-72

Yu Y., Liu S., Wang W., Song W., Zhang M., Zhang W., Qin Z., Cao X. (2002) Involvement of tumour necrosis factor-alpha-related apoptosis-inducing ligand in enhanced cytotoxicity of lipopolysaccharide-stimulated dendritic cells to activated T cells. Immunology, 106(3): $308-315$

Yue Z., Liu Y., Ruan J., Zhou L., Lu Y. (2012) Tumor-associated macrophages: a novel potential target for cancer treatment. Chinese Medical Journal, 125(18): 3305-3311 
Zaini J., Andarini S., Tahara M., Saijo Y., Ishii N., Kawakami K., Taniguchi M., Sugamura K., Nukiwa T., Kikuchi T. (2007) OX40 ligand expressed by DCs costimulates NKT and CD4+ Th cell antitumor immunity in mice. Journal of Clinical Investigation, 117(11): 3330-3338

Zajonc D.M., Girardi E. (2015) Recognition of microbial glycolipids by natural killer T cells. Frontiers in Immunology, 6: 400

Zhang N., Sadun R.E., Arias R.S., Flanagan M.L., Sachsman S.M., Nien Y.-C., Khawli L.A., Hu P., Epstein A.L. (2007) Targeted and untargeted CD137L fusion proteins for the immunotherapy of experimental solid tumors. Clinical Cancer Research, 13(9): 2758-2767

Zhdanova N.S., Rubtsov N.B., Minina Yu.M. (2007) Terminal regions of mammal chromosomes: Plasticity and role in evolution. Russian Journal of Genetics, 43(7): 721-732 